\title{
Establishing National Carbon Emission Prices for China
}

\author{
Chia-Lin Chang \\ Department of Applied Economics Department of Finance \\ National Chung Hsing University, Taiwan \\ Te-Ke Mai \\ Department of Economics National Tsing Hua University, Taiwan
}

\author{
Michael McAleer \\ Department of Finance Asia University, Taiwan and \\ Discipline of Business Analytics University of Sydney Business School, \\ Australia And Econometric Institute, Erasmus School of Economics \\ Erasmus University Rotterdam, The Netherlands and \\ Department of Economic Analysis and ICAE Complutense University \\ of Madrid, Spain and Institute of Advanced Studies \\ Yokohama National University, Japan
}

\begin{abstract}
The purpose of the paper is to establish national carbon emissions prices for the People's Republic of China, which is one of the world's largest producers of carbon emissions. Several measures have been undertaken to address climate change in China, including the establishment of a carbon trading system. Since 2013, eight regional carbon emissions markets have been established, namely Beijing, Shanghai, Guangdong, Shenzhen, Tianjin, Chongqing, Hubei and Fujian. The Central Government announced a national carbon emissions market, with power generation as the first industry to be considered. However, as carbon emissions prices in the eight regional markets are very different, for a variety of administrative reasons, it is essential to create a procedure for establishing a national carbon emissions price. The regional markets are pioneers, and their experience will play important roles in establishing a national carbon emissions market, with national prices based on regional prices, turnovers and volumes. The paper considers two sources of regional data for China's carbon allowances, which are based on primary and secondary data sources, and compares their relative strengths and weaknesses. The paper establishes national carbon emissions prices based on the primary and secondary regional prices, for the first time, and compares both national prices and regional prices against each other. The carbon emission prices in Hubei, Guangdong, Shenzhen and Tianjin are highly correlated with the national prices based on the primary and secondary sources. Establishing national carbon emissions prices should be very helpful for the national carbon emissions market that is under construction in China, as well as for other regions and countries worldwide.
\end{abstract}

Keywords Pricing Chinese carbon emissions, National pricing policy, Energy, Volatility, Energy finance, Provincial decisions.

JEL Classification $\quad$ C22, C58, G12, Q35, Q48.

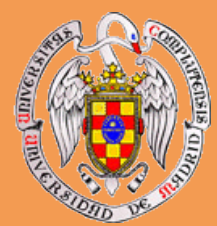

Working Paper no 1810

March, 2018

UNIVERSIDAD

COMPLUTENSE

MADRID

ISSN: 2341-2356

WEB DE LA COLECCIÓN: http://www.ucm.es/fundamentos-analisis-economico2/documentos-de-trabajo-del-icaeWorking papers are in draft form and are distributed for discussion. It may not be reproduced without permission of the author/s. 


\title{
Establishing National Carbon Emission Prices for China *
}

\author{
Chia-Lin Chang \\ Department of Applied Economics \\ Department of Finance \\ National Chung Hsing University, Taiwan \\ Te-Ke Mai \\ Department of Economics \\ National Tsing Hua University, Taiwan \\ Michael McAleer ** \\ Department of Finance \\ Asia University, Taiwan \\ and \\ Discipline of Business Analytics \\ University of Sydney Business School, Australia \\ and \\ Econometric Institute, Erasmus School of Economics \\ Erasmus University Rotterdam, The Netherlands \\ and \\ Department of Economic Analysis and ICAE \\ Complutense University of Madrid, Spain \\ and \\ Institute of Advanced Studies \\ Yokohama National University, Japan
}

Revised: March 2018

* For financial support, the first author wishes to acknowledge the Ministry of Science and Technology (MOST), Taiwan, and the third author is grateful to the Australian Research Council and the Ministry of Science and Technology (MOST), Taiwan.

** Corresponding author: michael.mcaleer@gmail.com 


\begin{abstract}
The purpose of the paper is to establish national carbon emissions prices for the People's Republic of China, which is one of the world's largest producers of carbon emissions. Several measures have been undertaken to address climate change in China, including the establishment of a carbon trading system. Since 2013, eight regional carbon emissions markets have been established, namely Beijing, Shanghai, Guangdong, Shenzhen, Tianjin, Chongqing, Hubei and Fujian. The Central Government announced a national carbon emissions market, with power generation as the first industry to be considered. However, as carbon emissions prices in the eight regional markets are very different, for a variety of administrative reasons, it is essential to create a procedure for establishing a national carbon emissions price. The regional markets are pioneers, and their experience will play important roles in establishing a national carbon emissions market, with national prices based on regional prices, turnovers and volumes. The paper considers two sources of regional data for China's carbon allowances, which are based on primary and secondary data sources, and compares their relative strengths and weaknesses. The paper establishes national carbon emissions prices based on the primary and secondary regional prices, for the first time, and compares both national prices and regional prices against each other. The carbon emission prices in Hubei, Guangdong, Shenzhen and Tianjin are highly correlated with the national prices based on the primary and secondary sources. Establishing national carbon emissions prices should be very helpful for the national carbon emissions market that is under construction in China, as well as for other regions and countries worldwide.
\end{abstract}

Keywords: Pricing Chinese carbon emissions, National pricing policy, Energy, Volatility, Energy finance, Provincial decisions.

JEL: C22, C58, G12, Q35, Q48. 


\section{Introduction}

As climate change has increasingly become a critical environmental, political and economic phenomenon, many countries and international organizations have taken action in response. As China is one of the world's largest manufacturing countries, and the most significant emitter of carbon emissions, the Central Government of the People's Republic of China has taken a series of decisive actions to reduce regional and national carbon emissions.

The measures include the development of clean energy, reducing the use of coal, and emphasizing the reduction of carbon emissions through the establishment of a carbon emissions trading system, among others. Of these measures, establishing regional carbon emissions markets, with the intention of establishing a national carbon emissions market, is a very important step toward reducing carbon emissions.

In 2011, the Central Government of China proposed a plan to establish seven regional carbon emissions markets, namely Shenzhen, Guangdong, Beijing, Shanghai, Hubei, Tianjin and Chongqing. Based on the experience of these regional markets, China intends to establish a national carbon emissions market. In mid-2013, the first regional carbon emissions market, namely the Shenzhen carbon emissions market, was established, followed in late-2013 by the Beijing, Guangdong, Shanghai and Tianjin regional markets. The Chongqing and Hubei regional markets were established in 2014 and, in early-2017, the Fujian market was established. By late-2017, carbon emissions permits have been traded in eight regions, and about 0.13 billion tons of carbon emission permits, worth approximately 2.7 billion yuan, have been traded.

Of the eight regional markets, Beijing, Shanghai, Shenzhen and Tianjin are large cities, while Guangdong, Hubei, Chongqing and Fujian are huge provinces. The sizes of the manufacturing industries in these markets are different. Beijing, Shanghai, Tianjin, Shenzhen, Guangdong and Fujian are located in the east of China, while Hubei and Chongqing are situated in the mid-west of the country.

Generally, the eastern seaboard has advanced technology, more efficient governments and markets, and greater access to international markets. Beijing, Shanghai, Shenzhen and Guangdong have larger and more efficient economic and financial markets, and greater access to private and corporate investments. Different regions and provinces own different manufacturing industries. For example, the manufacturing industries in Shenzhen are primarily light industries with advanced technology while, in the Hubei 
province, in 2016 more than $60 \%$ of the regional income from manufacturing was contributed by heavy industry.

Owing to such differences across the regions, the carbon emissions prices in these markets are also quite different. The prices in Beijing are stable and essentially vary around 50 yuan, while the prices in Shanghai are around 30 yuan before 2015 and after 2016. The prices in Guangzhou start from 60, and decline to 15 yuan, while the prices in Tianjin start from 30 yuan and decline to less than 10 yuan. The prices in Chongqing start from 30 yuan and decline to virtually 0 yuan. The price in Shenzhen and Fujian vary around 25 yuan after 2016, and the prices in Hubei vary around 15 yuan after 2016. The highest mean price of the eight regional markets is 50.06 in Beijing, while the lowest mean price is 17.42 yuan in Chongqing (see Table 1).

Differences in the prices of carbon emissions lead to differences in costs to companies, both regionally and nationally. By the end of 2017, the prices in Beijing, Shanghai, Guangdong, Shenzhen, Tianjin, Chongqing, Hubei and Fujian were 54, 35, 12.91, 29, 8.51, 9.52, 15.63 and 21.79 yuan, respectively. These prices reflect the costs of carbon emissions to companies in Beijing being about 1.5 times the cost to companies in Shanghai, 4 times the cost to companies in Guangdong, 1.9 times the cost to companies in Shenzhen, 6 times the cost to companies in Tianjin, 5.7 times the cost to companies in Chongqing, 3.5 times the cost to companies in Hubei, and 2.5 times the cost to companies in Fujian, none of which suggests a level playing field for companies in terms of mitigating carbon emissions.

It is clear that companies in Beijing currently pay higher prices for carbon emissions than do companies in the other seven regions. If China establishes a national carbon emissions market, the prices in all the regions and provinces will be equalized. Such a notional "national price" may be inherently too low for companies in Beijing, or too high for companies in Tianjin and Chongqing.

A national carbon emissions market will require participation by all companies in the 40 provinces in China. All these provinces and regions, most of which do not presently have regional carbon emissions markets, may have notional regional prices that might not be reflected in the national prices. How to establish and calculate carbon emissions prices for the national market to achieve the carbon emissions reduction targets and maximize social welfare is a meaningful issue for the Central Government of China, as well as for other regions and countries worldwide. 
Not only do the prices in the regional markets have substantial differences, but so too do the corresponding turnovers and volumes. Hubei is one of the most important regional markets as measured by turnover. In the period from mid-2014 to late-2017, Hubei has the largest daily average trading turnover, at 930000 yuan, which is approximately 30 times that of Chongqing and 20 times that of Tianjin. Both the total turnover and volume for Hubei are very large. The daily average trading turnover of Guangdong and Shenzhen are also huge, at 650000 and 690000 yuan, respectively. The daily average trading turnover of Fujian is 230000 yuan, but the Fujian market only started in 2017, so that the total turnover and volume of the Fujian market is small in comparison with the other much larger regional markets. Therefore, although Fujian can be safely ignored at the present time in terms of establishing national carbon emissions prices, Hubei cannot be ignored.

In order to obtain national prices, we need the information that is available and accessible in the regional markets. A national price should be closely related to the prices, turnovers and volumes in the eight regional markets, so it is necessary to access the data for regional prices, turnovers and volumes. At present, most of the available data are provided by regional exchanges and some private investment or research organizations. Beijing, Shanghai, Guangdong, Shenzhen, Tianjin and Chongqing mainly provide their own market data. Hubei provides its own market data, as well as the data for the other regional markets, but Hubei only provides the data for 200 of the most recent trading days. Fortunately, some secondary data sources, such as the Hong Kong Emission Exchange and China Carbon Emission Trading website, provide data for all eight regional markets.

Both the primary and secondary data sources have their advantages and disadvantages. Moreover, they do not rely on identical sources of data because of different data processing methods and different methods of recording the data. The primary data may be more reliable but not always straightforward to use in practice. The secondary data are easier for use in research and investment decision making, and provide some important and useful information that primary data do not provide.

As an example, in the case of Hubei, all the daily data are available from secondary sources. As mentioned above, Hubei is too large and important to be ignored. For these reasons, both the primary and secondary data are useful and will be used in establishing and calculating national carbon emissions prices. 
In this paper, we compare and contrast the primary and secondary data on turnovers, volumes and prices in the six regional markets carefully. The primary differences between the two data sets are shown. Differences in the data can be separated into two types: (i) the first type of difference arises from using different data processing methods; and (ii) the second type of difference is caused by different recording methods arising from the two data sources.

Furthermore, the paper uses both primary data (from six regional markets) and secondary data (from the original six regional markets, together with Hubei as a seventh region) to establish national prices, and compare them with regional prices and each other. It is found that establishing national carbon emissions prices using primary data is substantially different from establishing national carbon emissions prices using secondary data.

Moreover, establishing national prices using secondary data tends to be more stable than establishing national prices using primary data, primarily because the Hubei regional market is too important to be ignored. We establish and calculate national carbon emissions prices from mid-2014 to late-2017. Both national prices have important reference value to the national carbon emissions market in China that is presently under construction.

The remainder of the paper is as follows. Section 2 presents a review of the sparse literature on carbon emissions prices, returns and volatility, especially as it applies to China. Sections 3 discusses primary and secondary sources of carbon emissions data in China. Section 4 evaluates the descriptive statistics of the regional data. Primary data for five regions and secondary data for six regions are compared in Section 5. A method for establishing national carbon emissions prices based on regional prices is presented in Section 6. National prices based on primary and secondary regional data sources, using six and seven regional prices, are established in Sections 7 and 8, respectively. National prices based on primary and secondary sources are compared in Section 9. Some concluding remarks are given in Section 10.

\section{Literature Review}

They would seem to be only a few published papers that discuss the prices, returns and volatility of carbon emissions, with even fewer that review and discuss carbon emissions and their associated derivatives, such as spot and futures prices of financial returns, especially for China. The sub-discipline of empirical finance, energy finance 
and financial econometrics is clearly a rich area for future research in determining national spot prices, as well as national and regional futures prices, and the volatility associated with the returns on national and regional spot and futures prices.

Cetin and Verschuere (2009) propose a model and calculate the spot price of Euro carbon emissions permits under the assumptions of no banking and exogenous prices. The authors suggest how the model might be extended to carbon pricing with banking, and determine optimal hedging formulas with minimum local risk. Though not stated in the paper, research might also be extended to incorporate futures prices, and the associated volatility of spot and futures returns.

Bohringer et al. (2014) decompose the leakage and terms-of-trade motives for carbon emissions price differentiation under the framework of optimal taxes and international spillovers, and use it to analyse empirical data. The authors find that uniform carbon emissions pricing will provide a better guideline for unilateral climate policy making, in practice.

Reboredo (2014) use a multivariate conditional autoregressive range-based volatility model to examine the dynamics of volatility spillovers between carbon emissions permits and oil markets in the European Union carbon emissions market. The authors find that there are not significant volatility spillovers between the carbon emissions and oil markets.

Chang et al. (2017) use the multivariate conditional volatility BEKK model and a Granger causality test to capture the dynamic conditional volatility spillovers and causality between carbon emissions, and oil and coal spot and futures for the European Union and USA. The authors develop a likelihood ratio test statistic to test the Diagonal BEKK model as the null hypothesis against the alternative hypothesis of a Full BEKK model. Chang and McAleer (2018) provide the structural regularity and asymptotic properties of these models when they can be shown to exist.

There are also some papers that focus on carbon emissions and the carbon market in China. Zhang and Cheng (2009) use the Granger causality test and multivariate economic model to investigate the relationships between economic growth, energy consumption and carbon emissions in China. Dhakal (2009) investigate the contribution of urban energy use and carbon emissions from cities in China, and discuss the possible alternative policy implications regarding energy. Lia and 
Colombier (2008) address the management of carbon emissions in China through building energy efficiency, and provide reasonable options.

Lo (2013) analyses whether carbon trading markets can work well in the political and economic system in China, which is substantially different from much older capitalistic economic systems. Lo (2016) analyses four significant challenges in the carbon emissions trading market in China, and offer several solutions.

There is presently no research that has focused on the regional carbon emissions markets in China, and particularly a national carbon emissions price. A national price will be essential component of the national carbon emissions market that is presently under construction in China.

In this paper, we discuss two sources of regional carbon emissions prices in China, which are based on primary and secondary sources of data. The advantages and disadvantages of the two regional data sources are analysed and compared. We also calculate, for the first time, national carbon emissions prices for China using the primary and secondary data. Establishing national carbon emissions prices should be very helpful for the national carbon emissions market that is under construction in China, as well as for other regions and countries worldwide.

\section{Primary and Secondary Sources of Data}

There are two sources of regional carbon emissions prices in China, namely primary and secondary data. The primary data sources are basically the official websites of the regional carbon exchanges, such as the Shenzhen Carbon Exchange, Shanghai Environment and Energy Exchange, Hubei Emissions Exchange, and so on. The secondary data sources are obtained from investment companies or consulting agencies. One of the most important secondary data sources is the China Carbon Information Technology Research Institute, which provides daily data for eight regional carbon emissions markets.

As only 200 observations on carbon emissions primary prices are available for Hubei, it is necessary to access the carbon emissions secondary price data sources if data from Hubei are to be used in calculating the China national carbon price. Moreover, the primary data for Fujian is no longer available, despite this market having been established in early 2017. As the turnover and volume for Fujian is very small 
compared with other markets, data for Fujian will not be used in calculating the national carbon emissions prices for China.

The primary data sources are generally more reliable than their secondary counterparts as they are obtained directly from the regional exchanges. Nevertheless, some problems exist with respect to the primary data sources. First, each regional data source provides daily data for its own market and not the other regional markets, so it is not convenient to compare primary data across the regional markets. Second, some primary data sources provide data for non-zero observations, such as the China Tianjin Emissions Exchange. This source has the effect of making the length of the data period shorter as there are many zero observations in some regional markets, thereby making any comparisons difficult across regional markets.

One advantage of the secondary data sources is that they can be used in comparing across the regional markets. The China Carbon Information Technology Research Institute provides daily data for eight regional markets, whereby the data are accessible for the same sample period. However, the secondary data sources are not as reliable as the primary data sources. The primary data are more accurate for purposes of research and making investment decisions, whereas the secondary data sources may be less reliable but can be used for making regional comparisons. For these reasons, it is essential to compare the primary and secondary data sources and the data themselves.

Primary data are available for the six regional markets in Shenzhen, Beijing, Shanghai, Guangdong, Tianjin and Chongqing. Secondary data of eight regional markets can be downloaded from the website of the China Carbon Information Technology Research Institute. In Tables 4-9, T1, V1 and P1 denote turnovers, volumes and prices from the primary data sources, respectively, while T2, V2 and P2 denote turnovers, volumes and prices from the secondary data sources, respectively. All the data are from the established days of regional markets to the end of 2017, so the sample data periods for the regional markets are different.

\section{Descriptive Statistics}

As the eight regional markets in China were established at different times, they have different sample data periods and numbers of observations. In general, the earlier a market is established, the larger should be the number of sample observations. However, due to the different trading frequencies in different regional markets, it is 
possible that some markets with shorter sample periods will have more non-zero observations than other markets with longer sample periods.

The Shenzhen market was established in mid-2013 and, as the first carbon market in China, it has the largest number of observations. Shanghai, Beijing, Guangdong and Tianjin were established in late-2013, Chongqing and Hubei were established in mid-2014, and Fujian was established in 2017. As the Fujian market was established only one year ago, its trading period is short, with relatively few observations. As it is not important in calculating national carbon emissions prices for china, the focus will be on discussing and comparing data from the other seven regional markets.

For a number of reasons, some of them unknown and unexplained, some markets such as Tianjin and Beijing only publish their non-zero trading records in the primary data sources. The number of working days from late-2013 to late-2017 is around 1000 days, but the primary data sources only provide 651 observations for Beijing, 861 observations for Shanghai, 461 observations for Tianjin, and 735 observations for Guangdong. Therefore, the data might not appear to be daily as too many observations may have been deleted.

There is another problem in using primary data sources in comparing and calculating national prices for China. Some regional markets added trading days on some weekends, such as Guangdong, which added six extra days, Beijing, which added seven extra days, and Shenzhen, which added eleven extra days, whereas Shanghai did not add any extra days. Therefore, in order to undertake appropriate comparisons in calculating the national prices, it is necessary to accommodate the extra trading days in some of the regions. A simple way of dealing with these additional data points is to delete these observations altogether.

Compare with the primary data sources, a problem also exists in the secondary data sources. The most important secondary data source is the China Carbon Information Technology Research Institute, which provides about 1200 observations for Beijing, 1180 observations for Shanghai, 1170 observations for Tianjin, and 1180 observations for Guangdong. As the numbers of these observations are significantly greater than the numbers of trading days in the corresponding regional markets, there is clearly an error in compiling some of the secondary data.

By comparing the numbers of non-zero observations from the primary and secondary data sources, it can be determined that the numbers of non-zero observations in the 
primary and secondary data are almost the same. The problem in the primary data is that there are too many missing zero observations. The secondary data have a problem of too many zero observations because some zero observations have been added to weekends for the primary data.

In order to compare the primary and secondary data meaningfully, we add zero values to turnovers, volumes and the previous value of prices for the missing trading days, and delete the added observations for the weekends in the primary data sample. After processing according to this procedure, the primary and secondary data samples are of the same length. For the seven regional markets, there are 1067 observations for Beijing, 922 observations for Chongqing, 1052 observations for both Guangdong and Shanghai, 1183 observations for Shenzhen, 1047 observations for Tianjin, and 978 observations for Hubei. This enables a sensible analysis of the regional turnovers, volumes, and prices, as given below.

From Table 1, which gives the descriptive statistics for regional prices, Beijing has the highest mean price at 50.06 yuan, followed by Shenzhen at 42.65 yuan. The mean prices of Guangdong and Shanghai are close at 24.29 and 24.79 yuan, respectively. The mean prices of Hubei and Tianjin are also close at 20.22 and 19.99 yuan, respectively. Chongqing has the lowest mean price at 17.42 yuan. The median prices are reasonably similar to those of the respective mean prices.

Shenzhen has a high maximum price at 122.97 yuan, followed by Beijing and Guangdong, both at 77 yuan, followed by Shanghai, Tianjin and Chongqing, at 44.91, 50.11 and 47.52 yuan, respectively. The lowest maximum price is for Hubei at 29.3 yuan. Shanghai has a very low minimum price at 0.085 yuan, followed closely by Chongqing at 1 yuan. The minimum prices for Shenzhen, Guangdong, Tianjin and Hubei are 2.12, 6.93, 7 and 10.07 yuan respectively.

Table 1 also indicates that the Hubei price is most stable, with a standard deviation of 4.45, followed by Beijing at 6.35, and Tianjin at 7.74. Shanghai, Shenzhen, Guangdong and Chongqing all have standard deviations greater than 10, at 12.03, 18.15, 17.80 and 11.71, respectively. The Shenzhen price varies the most among the seven markets, with a standard deviation of 18.15 .

The skewness coefficients indicate that most markets are reasonably symmetric, but the kurtosis suggest there are departures from normality. 


\section{[Table 1 goes here]}

From Table 2, which gives the descriptive statistics for regional turnovers, Hubei has the largest mean turnovers at 932969 yuan, so that the Hubei market trades more carbon permits than other markets, on average. The second and third largest mean turnovers are Shenzhen and Guangdong, at 690989 and 655539 yuan, respectively. From the perspective of mean turnovers, Hubei, Guangdong and Shenzhen are the three most importance carbon markets. The mean turnovers of Shanghai and Beijing follow next, at 409556 and 331946 yuan, respectively, so that, while Shanghai and Beijing are not as large as the leading three markets, they still play importance roles, bases on average turnovers. The two smallest mean turnovers are in Tianjin and Chongqing, at 47955 and 29514 yuan, which are about 5\% and 3.2\% of Hubei, respectively. The Tianjin and Chongqing markets are not important, based on average turnovers.

The median turnovers are considerably lower than those of the respective mean turnovers, reflecting the large extreme values and high standard deviations. Even though Hubei has the largest mean turnover, Shenzhen has the greatest maximum turnover at 100000000 yuan. Guangdong has the second highest maximum turnover at 47519182 yuan, which is much smaller than for Shenzhen. The third largest is Hubei at 29598300 yuan. The maximum turnovers of Beijing, Shanghai and Tianjin are 7238610, 23174943 and 11206984 yuan, respectively. The smallest maximum turnover is for Chongqing at 4457300 yuan. This is not especially surprising as Chongqing has relatively few trades. The minimum turnovers in all seven markets are zero, which would seem to suggest that the regional carbon markets lack liquidity.

Shenzhen not only has the largest maximum turnover, but also the largest fluctuations in turnovers, with a standard deviation of 4077118, which is much greater than the second market, Guangdong, with a standard deviation of 2370102. The standard deviations of Hubei and Shanghai are 1972580 and 1697093, respectively. The lowest standard deviations are for Tianjin and Chongqing, as expected, with standard deviations of 500858 and 224810, respectively. These relatively low values are not surprising as there are few trades in Tianjin and Chongqing. It is worth noting that Beijing has the smallest fluctuations among the five important markets. The standard deviation for Beijing is 926834, which is much smaller than for Shenzhen. This might be due to the reasonable supply of liquidity and the strict participation limits in Beijing. 
The skewness and kurtosis coefficients indicate that all seven regional markets have significant departures from normality.

\section{[Table 2 goes here]}

The descriptive statistics for regional volumes are given in Table 3, which indicates that Hubei has the largest carbon market based on the mean, at 47372 tons, followed closely by Guangdong at 45350 tons. The other five markets are much smaller than Hubei and Guangdong, based on mean volumes, with Shanghai and Shenzhen close, at 25578 and 23437 tons, respectively. The mean in the Chongqing market is 8865 tons, which is larger than in Beijing and Tianjin. This result is perhaps a little surprising, but is nevertheless understandable given the large supply of Chongqing permits. The two smallest markets based on mean volumes are Beijing and Tianjin, at 6588 and 3419 tons, respectively.

The median volumes are considerably lower than those of the respective mean volumes, reflecting the large extreme values and high standard deviations.

The Shenzhen market has the largest maximum turnover, it also has the largest maximum volume at 4000000 , followed by Guangdong at 3712999 and Chongqing at 2112607 tons, respectively. The maximum volumes of Shanghai and Hubei are 1380000 and 1176000 tons. Tianjin and Beijing have the smallest maximum volumes, which are about 827815 and 154960 tons, respectively. The minimum volumes in all seven markets are zero, which is consistent with the regional carbon markets lacking liquidity.

Shenzhen has the largest maximum volume and the second largest standard deviation, while Guangdong has the second maximum volume and the largest standard deviation. On the other hand, Beijing has the smallest maximum volume and the smallest standard deviation. The fluctuations in Shanghai, Hubei and Chongqing based on volume are close, with standard deviations of 102684, 92212, and 82367, respectively. The Tianjin volume has a standard deviation of 39359, which is the second lowest fluctuating market to Beijing.

The skewness and kurtosis coefficients indicate that all seven regional markets have significant departures from normality. 
In general, the prices of the seven markets fluctuate much less than their respective turnovers and volumes. Taking Shenzhen as an example, the standard deviation of price is about 18.15, and the standard deviations of turnover and volume are 4077118 and 166807, which are approximately 224600 and 9200 times the standard deviation of price. This result may indicate that the pricing function in the regional carbon markets is far from perfect as changes in demand and supply do not seem to be able to affect prices appreciably.

\section{[Table 3 goes here]}

\section{Comparisons of Primary and Secondary Data}

As the regional primary and secondary carbon emissions data have advantages as well as disadvantages, it is essential to compare them over the same sample period. In so doing, some trading days are deleted in Guangdong, Beijing and Shenzhen to ensure that all regional markets have the same number of observations.

\subsection{Beijing}

Figure 1 shows that for Beijing prices, primary and secondary data are highly correlated, with the plots of both series almost overlapping each other. Nevertheless, secondary data have some prices that are markedly different from the primary data. The greatest differences occur on 17 July 2017 and 20 July 2017 where, for secondary data, the prices are 35, and for the primary data, the prices are 42. During these two days, there are no transactions of Beijing permits, so we fixed the prices by using the previous prices for the primary data, so that the prices on 16 July 2017 and 21 July 2017 are both 42. It would seem sensible to use the previous prices in such cases, especially as different processing methods can lead to different prices for the no transaction days. Such administrative circumstances might not accurately capture the inherent differences in the primary and secondary data, but rather the different methods of processing the data.

This is the first reason for the differences arising from the two sources of data, which will arise in the other regional markets to be discussed below.

[Figure 1 goes here]

For observations such as 28 December 2017, the turnover and volume of the primary data are both zero. For the secondary data, the turnover is 901955 and volume is 
19999, which reflects the real differences between the two data sources. Even though the China Carbon Information Technology Research Institute claims that their data are sourced from the regional exchanges, their data are nevertheless slightly different from the primary data. For such differences, using the primary data would seem to be more appropriate. Data for the other six regional markets show that such differences also exist.

This is the second reason for the differences arising from the two sources of data, which will arise in the other regional markets to be discussed below.

From Table 4, we can see that the correlation between the primary and secondary data is high at 0.986. The correlation between V1 and V2 is 0.994, and the correlation between T1 and T2 is 0.993, which suggests that turnovers and volumes, respectively, in the primary and secondary data are also highly correlated. Although the correlations between the primary and secondary turnovers and volumes are higher than those for the prices from two data sources, all three correlations are very high.

\section{[Table 4 goes here]}

Table 4 and Figure 1 show that turnovers, volumes and prices arising from the two data sources are very similar, but the turnovers and volumes of two data sources are more highly correlated than are the prices, which may well arise from the different processing methods for the zero observations. In short, the primary and secondary data for Beijing are similar and highly correlated, but using primary data for research and investment decisions may be more reliable.

\subsection{Shanghai}

Figure 2 shows that the primary and secondary data for Shanghai are not as closely related as they are for Beijing. There are at least six observations where the secondary data are markedly different from the primary data. One substantially different observation occurs on 30 June 2014, when the primary price is 39.41 and the secondary price is 48. This arises from the second type of difference, as mentioned above. As the turnover and volume in the primary data are both zero, the price is set at the previous price. However, the turnover and volume in the secondary data are 346560 yuan and 7220 tons, respectively. Moreover, as the turnovers and volumes in the primary and secondary data are both zero for the following several days, both 
sources use the previous price for the same following days. Consequently, different prices are recorded from the primary and secondary sources.

\section{[Figure 2 goes here]}

The second different observations occur on 29 and 30 October 2015. The turnovers and volumes of the two days for the secondary data are both zero but, for the primary data, the turnovers are 1980000 and 1800000 yuan, and the volumes are 110000 and 100000 tons, respectively, on the two days. As a result, the prices for the two days are 18 yuan for the primary data, but 12.5 for the secondary data. The differences between the two data sources for 30 October 2015 arise from the second type of difference, as mentioned above.

The third different observation occurs on 27 November 2015, which also arises from the second type of difference. The turnover and volume for the primary data are 101500 yuan and 5000 tons, while the turnover and volume from the secondary data are 151500 yuan and 5000 tons, respectively. Interestingly, the observation has the same volume but different turnovers, which leads to different prices in the primary and secondary data sources.

The fourth different observations occur between 4 July 2016 to 17 November 2016, and arises from the first type of difference, as mentioned above. We use the previous price for the zero trading days in the primary data, which is 8.79 yuan, while the secondary data is set at 9.8 for the zero trading days. The prices might not appear to be substantially different, but using the previous prices for the zero trading days would seem to be more reasonable.

The fifth different observation occurs on 13 February 2017. The prices of 13, 14 and 15 February 2017 are 3.58, 0.23 and 1.43, respectively, for the primary data, while the secondary data has prices that are 38.83, 37.86 and 39, respectively. There are huge differences between the prices in the primary and secondary data, which arises from the second type of difference. The turnovers for the three days are 1970413.21, 115630.9 and 1054507.1 yuan for the primary data, and 1970410, 115631 and 250670 yuan for the secondary data. The volumes for the three days are 550821, 503054 and 737161 tons, respectively, and 50821, 3054 and 6400 tons for the secondary data. It is worth noting that, on 13 February and 14 February 2017, the turnovers for the primary and secondary data are the same, but the volumes for the secondary data are much smaller than they are for the primary data. 
A similar situation occurs on 15 June and 16 June 2017. The prices for the two days are 11.18 and 7.38 yuan for the primary data, but 33.17 and 34.5 for the secondary data, respectively. This is a huge second type of difference. The turnovers for these two days are 8340451.5 and 4691859.6 yuan for the primary data, and 459214 and 1191860 yuan for the secondary data, respectively. The volumes for these two days are 745976 and 635965 tons for the primary data, and 13501 and 35965 tons for the secondary data, respectively. Although the prices for the secondary data fluctuate less than for the primary data, the latter are more reliable and provides additional information, such as prices that are obtained from negotiated transactions.

Table 5 indicates that, the prices between the primary and secondary data are highly correlated, at 0.959, although they are not as highly correlated as in Beijing. The correlation between the turnovers for the primary and secondary data are rather low at 0.596, which is much lower than the correlation between the prices. The correlation between the volumes for the primary and secondary data is even lower at 0.554. It seems that turnovers and volumes for the primary and secondary data are less correlated, so using the secondary data might lead to serious errors in research or investment decision making based on turnovers and volumes. Nevertheless, the prices for the primary and secondary data are still highly correlated, though it would seem that using the primary data may be more reliable.

\section{[Table 5 goes here]}

\subsection{Guangdong}

Figure 3 indicates that the plots of the primary and secondary prices are very similar, with only minor differences throughout the sample. One difference occurs on 31 December 2015, where the primary price is 18.13 and the secondary price is 18.85 . This is, in fact, a mistake in the secondary data because, on that day, turnovers and volumes are the same in the primary and secondary markets, at 41654.65 yuan and 2297 tons, respectively, so the primary and secondary prices should also be the same at 18.13 yuan, though they are not.

\section{[Figure 3 goes here]}

The second different observation occurs on 6 January 2016, where the primary price is 18.13 and the secondary price is 15.1 . This is the second type of difference. The 
turnover and volume for the primary data are both zero, while the turnover and volume for the secondary data are 15100 yuan and 1000 tons, respectively, on that day. A similar situation also occurs on 25, 28 and 29 November and 2 December 2016. The prices for the primary data on these days are 10.72, 11.33, 11.20 and 10.7, respectively, while the prices for the secondary data are 11.21, 17.02, 12.45 and 15, respectively. The differences arise because of the different turnovers and volumes in the primary and secondary data.

Table 6 shows that P1 and P2 are very highly correlated, at 0.998. The correlation between T1 and T2 is 0.624 , and the correlation between V1 and V2 is 0.580 , so that T1 and T2, and V1 and V2, are not as highly correlated as are P1 and P2. If the emphasis is on prices, using primary or secondary data are very similar. However, if the focus is on turnovers and volumes, using primary data is quite different from secondary data, so the choice between the two sources could be crucial in research as well as in investment decision making.

Interestingly, P1 and V1 have a negative correlation, at -0.146, while for Beijing, P1 and V1 have a positive correlation, at 0.019. Price and supply should, in principle, have a negative relationship, which holds in the cases of Guangdong and Shanghai, at -0.146 and -0.182 , respectively. However, for Beijing, the relationship between the primary price and supply is positive, quite possibly because of the limited supply in Beijing of carbon emissions permits and the serious regulatory limitations of participating in the Beijing carbon emissions market. There is also a negative correlation between P2 and V2 for Guangdong and Shanghai, at -0.416 and -0.058 , respectively, while the correlation is positive for Beijing at 0.02 .

\section{[Table 6 goes here]}

\subsection{Tianjin}

The prices for the primary and secondary data are quite similar for Tianjin. From Figure 4, it is clear that the plots for P1 and P2 overlap for much of the ample period, except for four observations. The first observation occurs on 10 July 2015, with several different records, arising from the second type of difference. Prices on 3, 7, 9, and 10 July 2015 for the primary data are 15.9, 16.2, 14.31 and 16.75, respectively, while the secondary prices are 18.33, 19, 13.31 and 20.5, respectively. The differences arise from the different records of turnovers and volumes on these days. For several trading days after 10 July 2015, the turnovers and volumes for the primary 
and secondary data are all zero, so they both report the previous prices, which are 16.75 and 20.5, respectively.

\section{[Figure 4 goes here]}

The second observation occurs on 26 October 2015, where P1 is 24.09 yuan and P2 is 24.9 yuan, T1 and T2 are both 3372 yuan, and V1 and V2 are both 140 tons. Therefore, the correct price for the primary and secondary data should be 24.09 yuan, so it would seem that the secondary data has simply been reported incorrectly, rather than reflecting any differences in the underlying regional price.

The third observation occurs on 10 November 2016, when P1 is 15.05 yuan and P2 is 39.6 yuan. This is the first type of difference. The turnovers and volumes for the primary and secondary data are all zero, and the turnovers and volumes of many trading days before and after this day are also zero for the primary and secondary data. P1 and P2 for several days before and after this day are both 15.05. P1 uses the previous price and P2 may use the mean of the opening and closing prices. As there is no transaction on 10 November 2016, it might be more reasonable to use the previous price.

The fourth observation occurs on 5 June 2017, which is the second type of difference. T1 and V1 are 2756 yuan and 200 tons, respectively, while T2 and V2 are both zero, so that P1 is 13.78 and P2 is 13.55 . For several days after 5 June 2017, there are no transaction records for the primary and secondary data, so they both use the previous prices, at 13.78 and 13.55 , respectively.

As one-half of the differences between P1 and P2 arise from the first type of difference, it is possible to conclude that P1 and P2 are very similar. In fact, a similar conclusion can be discerned from Table 7. The correlation between P1 and P2 is very high at 0.991 , so that using P1 or P2 should lead to similar results. As distinct from Shanghai and Guangdong, T1 and T2 are almost as highly correlated as the prices, with a correlation of 0.933 , while V1 and V2 are even more highly correlated, with a correlation of 0.950 . It seems that for turnovers, volumes and prices, using the primary data would lead to similar outcomes from using the secondary data. Moreover, there are negative correlations between V1 and P1, at -0.067 , and between V2 and P2, at -0.063, which is consistent with what might be expected.

\section{[Table 7 goes here]}




\subsection{Chongqing}

Figure 5 shows that the plots of P1 and P2 are overlap closely. It seems that the prices for Chongqing are even more correlated than are the prices of Guangdong and Tianjin, with only three observations seemingly different. A crucial factor is that there are fewer than 300 non-zero observations. The first observation occurs on 26 September 2014, which is the first type of difference, with P1 at 30.74 yuan and P2 at 43 yuan. Analogous to the third different observation for Tianjin, the turnovers and volumes in the primary and secondary data are all zero. The primary data are based on the previous prices, while secondary data uses the mean of the opening and closing prices. As there is no transaction in 26 September 2014, using the previous price would seem to be the more reasonable approach.

\section{[Figure 5 goes here]}

The second observation occurs on 27 August 2015, which is the second type of difference, with P1 at 13.5 yuan and P2 at 15 yuan. The turnover and volume are 675 yuan and 50 tons, respectively, for the primary data, while turnover and volume are both zero for the secondary data. There are no transactions on the following 35 trading days. The primary and secondary data both use the previous price, at 13.5 and 1 yuan, respectively.

The third observation occurs on 4 January 2016, which is the second type of difference, with P1 at 12.5 yuan and P2 at 13 yuan. The turnover and volume are both zero for the primary data, while the turnover and volume are 3432 yuan and 264 tons, respectively, for the secondary data. Moreover, there are no transactions on the following 52 trading days. The primary and secondary data both use the previous price, at 12.5 yuan and 13 yuan, respectively.

Table 8 shows that P1 and P2 are very highly correlated, at 0.999 , which suggests that P1 and P2 are virtually the same throughout the sample. Moreover, T1 and T2 are reasonably highly correlated, at 0.830 , while V1 and V2 are more highly correlated, at 0.982. For prices and volumes, using the primary data is similar to using secondary data, whereas for turnovers, using the primary data could lead to different outcomes from using secondary data. Owing to a lack of transactions in Chongqing, prices in the primary and secondary markets are more similar than are the prices in the other regional markets. 


\section{[Table 8 goes here]}

\subsection{Shenzhen}

Shenzhen is the earliest carbon market in China, and has the largest number of observations. From Figure 6, there are at five observations with large differences between the primary and secondary data. The Shenzhen market is different from the other regional markets as it views permits in different years as different products. In order to compare Shenzhen with the other regional markets, we view all permits in different years as different products, and add the turnovers and volumes of different products on the same day to obtain an average price.

\section{[Figure 6 goes here]}

The first large difference is an observation that occurs on 21 August 2014, which is the second type of difference, with P1 at 55.05 yuan and P2 at 33.97 yuan. For the primary data, only SEA-2013 was traded, with turnover at 5560 yuan and volume at 101 tons. However, in the secondary data, both SEA-2013 (with turnover at 5560 yuan and volume at 101 tons) and SEA-2014 (with turnover at 374930 yuan and volume at 11101 tons) are traded. A similar outcome occurred on the following twelve days. For the primary data, there is only one product that is traded, namely SEA-2013. For the secondary data, there are two products that are traded, namely SEA-2013 and SEA-2014. With the trading record of SEA-2014, P2 is significantly smaller than is P1. When SEA-2014 was launched, its price was lower than SEA-2013. However, SEA-2014 and SEA-2013 are basically the same product, so they should have essentially the same price. As the market seems to need some time for the acceptance of a new product, treating permits in different years as different products may not necessarily be a sensible administrative outcome.

The second observation occurs on 20 July 2015, which is the first type of difference, with P1 at 34.22 yuan and P2 at 7.76 yuan. The different arises from different records of transactions on that day. For the primary data, the turnovers of SEA-2013, SEA-2014 and SEA-2015 are 1211.76, 122.71 and 0 yuan, respectively, and the volumes of the three products are 34, 5 and 0 tons, respectively. For the secondary data, the turnovers of the three products are 1211.76, 5 and 0 yuan, respectively, and the volumes of the three products are 34, 122.71 and 0 tons, respectively. It seems that the secondary data reverses the turnovers and volumes of the product, SEA-2014. 
Another simple error occurred on 19 February 2016, with P1 at 49.99 yuan and P2 at 5.07 yuan. For the primary data, the turnovers of SEA-2013, SEA-2014 and SEA-2015 are 0, 89.8 and 54000 yuan, respectively, and the volumes of the three products are 0, 2 and 1080 tons, respectively. For the secondary data, the turnovers of the three products are $0,89.8$ and 5400 yuan, respectively, and the volumes of the three products are 0,2 and 1080 tons, respectively. It is obvious that a mistake is reported for the secondary data, as the turnover of SEA-2015 should be 54000 instead of the incorrectly reported 5400 tons.

The fourth observation occurs on 28 November 2016, which is the second type of difference, with P1 at 23.52 yuan and P2 at 17.91 yuan. The difference arises from different reporting of the turnovers and volumes for the primary and secondary data. A similar situation arose on the following two days, namely 29 and 30 November 2016, with P1 at 23.71 yuan and 24.01 yuan, respectively, while P2 is at 23.21 yuan and 17.50 yuan, respectively.

A similar situation also occurred on 27 February 2017, which is the second type of difference, with P1 at 32.87 yuan and P2 at 7.05 yuan. For the primary data, the turnovers of SEA-2013, SEA- 2014, SEA-2015 and SEA-2016 are 62.6, 102.55, 66.4 and 31.39 yuan, respectively, and the volumes of the three products are 2, 3, 2 and 1 tons, respectively. For the secondary data, the turnovers of the three products are the same as the turnovers for the primary data, but the volumes of the three products are 31.3, 3, 2 and 1, respectively.

From Table 9, the correlation between P1 and P2 is 0.987, which is smaller than the correlations for Tianjin, Chongqing and Guangdong, but larger than for Shanghai and Beijing. The correlations between T1 and T2, and V1 and V2, are also high, at 0.972 and 0.947, respectively. It would seem that the outcomes from using the prices, turnovers and volumes based on primary data will be similar to those based on secondary data.

\section{[Table 9 goes here]}

In short, P1 and P2 are quite similar and highly correlated in all six regional markets. Among them, the prices for Chongqing are the most highly correlated, at 0.999, followed by Guangdong, at 0.998. The next highest correlations are for Tianjin, Shenzhen and Beijing, at 0.991, 0.987 and 0.987, respectively. The prices for 
Shanghai are the least highly correlated, at 0.959. In general, using the primary data for prices are likely to lead to similar outcomes to those arising from the secondary data.

For turnovers, T1 and T2 for Beijing are highly correlated, at 0.9, as well as for Tianjin and Shenzhen. The turnovers for Chongqing are not as highly correlated as the three other regions, at 0.830. The turnovers for Guangdong have a much lower correlation, at 0.624. The least correlated turnovers are for Shanghai, at 0.591. As a result, using the primary data for turnovers should lead to similar outcomes to those obtained from using the secondary data for Beijing, Tianjin and Shenzhen. However, for Chongqing, using the primary data might lead to different outcome from using the secondary data, whereas for Guangdong and Shanghai, using the primary data would likely lead to quite different outcomes from those arising from the secondary data.

For volumes, the outcomes are similar to those for turnovers. For Beijing, Tianjin and Shenzhen, using the primary data would lead to similar outcomes as for using the secondary data. For Chongqing, there would be some differences, while for Guangdong and Shanghai, using the primary data would lead to substantially different outcomes as compared with using the secondary data.

\subsection{Hubei}

As mentioned above, Hubei is an important regional market, and hence should be accommodated, if at all possible, in establishing national carbon emissions prices. Unfortunately, the Hubei exchange provides data for only the most recent 200 trading days, so that it is neither useful nor practical for purposes of calculating national carbon emissions prices, or for undertaking financial analysis. Fortunately, the secondary data sources provide more than 900 observations for the Hubei market, which is both useful and practical. As a result, it is not meaningful or sensible to compare the primary and secondary carbon emissions data for Hubei as the numbers of observations are substantially different.

Nevertheless, some discussion of the Hubei spot price for the secondary data is essential as Hubei is a very important regional market. From Figure 7, Hubei prices start at 21 yuan, increases to 30 yuan on 8 April 2014, and varies between 20 and 30 yuan from April 2014 through to April 2016. During this period, Hubei prices seems to be stable, after which there is a huge decline. On 15 July 2016, the price reaches its lowest point, at 10 yuan, increases substantially after the huge fall, reaches 20 yuan on 
6 December 2016, decreases over the following eight months, and varies around 25 yuan towards the end of 2017.

\section{[Figure 7 goes here]}

The changing pattern of Hubei prices during the sample period has a range of 20, and it is clear that the Hubei prices can be divided into two periods. In the period before April 2016, the price varies between 20 and 30 yuan, while in the period after April 2016, he price varies between 10 and 20 yuan. Overall, the change in Hubei prices are basically around 10 yuan in each period, and it would seem that Hubei prices are more stable than in most of the other regional markets. Therefore, calculating national carbon emissions prices including Hubei prices should lead to more stable prices than in the absence of Hubei.

\subsection{Fujian}

Analogous to the case of Hubei, it is not possible to compare the primary and secondary price data for Fujian because of the absence of primary data. The Fujian market is much smaller than are the markets for Hubei, Guangdong, Shenzhen, Shanghai and Beijing, based on turnovers and volumes. As the Fujian market was established in 2017, the number of observations is very short. Consequently, the Fujian market is not very useful for purposes of calculating national carbon emissions prices, and is thereby excluded in the calculation of national prices.

However, the Fujian market may be important in the future, as well as for research and in making investment decisions, so a description of Fujian prices in the secondary market might be useful. From Figure 8, Fujian prices are similar to those in Guangdong, namely by starting from a high price and declining to a much lower price. The price is initially 37 yuan, rising to more than 42 yuan on 15 February 2017, and varying between 35 and 40 until May 2017. The price begins to decline on 18 May, falling to 25 yuan on 1 June, increasing to 35 yuan on 8 June 2017. In the following three mouths, the price varies around 30 yuan, after which the price varies at around 25 yuan, and falls to 21.79 toward the end of 2017.

\section{[Figure 8 goes here]}

\section{Establishing National Prices for China}


On 19 December 2017, the China National Development and Reform Commission announced that China would begin to establish the National Carbon Market, and published a guiding document, namely "Development Scheme for National Carbon Market. (For Power Generation Industry)”. It is a gigantic step for carbon emissions reduction and trading in China, despite the establishment of a national market having been delayed on several occasions. However, there is still a long way to go for China to establish a national carbon emissions market. The Central Government of China plans to establish a national carbon emissions market for the power generation industry in 2018, while the establishment of national carbon emissions markets for the required eight industries is likely to take a further two to three years.

Price is the principle governing factor in the national carbon emissions market. According to the experience from carbon pricing in the various regions, the Central Government will provide a guiding price in the early stages of carbon pricing. However, the establishment of national carbon emissions prices for China raises very important theoretical and practical issues.

Regional markets are the pioneers of the proposed national carbon emissions market, so the experience and trading data from the eight regional markets will be helpful in establishing the national market. While the national carbon emissions market is under construction, the regional markets will play an important role in carbon emissions trading in terms of turnovers, volumes and prices as they effectively represent the national carbon emissions market. Therefore, the data from the regional markets should be used to calculate national carbon emissions prices.

There are two carbon trading strategies in the secondary market, namely electricity bidding and negotiated transactions. In all eight regional markets, the turnover is the sum of turnovers by electricity bidding $\left(T_{e}\right)$ and by negotiated transactions $\left(T_{n}\right)$. Similarly, the volume is the sum of volumes by electricity bidding $\left(V_{e}\right)$ and by negotiated transactions $\left(V_{n}\right)$. Consequently, the price is defined as follows:

$$
P_{i j}=\frac{T_{i j}}{V_{i j}}=\frac{T_{i j e}+T_{i j n}}{V_{i j e}+V_{i j n}}
$$

where $i$ denotes the region, $i=1,2,3,4,5,6,7$ representing Shenzhen, Beijing, Chongqing, Guangdong, Shanghai, Tianjin and Hubei, respectively, and $j=1,2,3, \ldots$. represents the trading days. 
The sample lengths of the regional markets are different. The Shenzhen market is the earliest regional market, and so has about 1200 trading days, while the Fujian market was established in early-2017, and so has fewer than 300 trading days. As the data of the Fujian market is not useful in establishing national prices, we use data from only seven regions in establishing the national prices.

Of the seven regional markets, Shenzhen has the largest number of trading days, while Chongqing has the fewest number of trading days. In calculating national prices, we need to use the data of a common period for the seven regional markets. As a result, the period for calculating national prices should be equal to the observations available in the Chongqing market, which starts from 19 June 2014.

As we have primary data for six regional markets, and secondary data for seven regional markets, we have two methods for calculating national prices. National prices based on primary data are defined as follows:

$$
\mathrm{NP}_{1 j}=\frac{\sum_{i=1}^{6} T_{1 i j}}{\sum_{i=1}^{6} V_{1 i j}}
$$

where 1 represents prices based on primary data, $i=1,2, \ldots, 6$ represents Shenzhen, Beijing Chongqing, Guangdong, Shanghai and Tianjin, respectively, and $j=1,2,3, \ldots$ represents trading days. $T_{1 i j}$ denotes the turnovers of province $i$ in trading day $j$ for primary data, and $V_{1 i j}$ denotes the volumes of province $i$ in trading day $j$ for primary data.

Similarly, national prices based on secondary data are defined as follows:

$$
N P_{2 j}=\frac{\sum_{i=1}^{7} T_{2 i j}}{\sum_{i=1}^{7} V_{2 i j}}
$$

where 2 represents prices based on secondary data, $i=1,2, \ldots, 7$ represents Shenzhen, Beijing Chongqing, Guangdong, Shanghai, Tianjin and Hubei, respectively, and $j=$ $1,2,3, \ldots$ represents trading days. $T_{2 i j}$ denotes the turnovers of province $i$ in trading day $j$ for secondary data, and $V_{2 i j}$ denotes the volumes of province $i$ in trading day $j$ for secondary data.

\section{Establishing National Prices Using Primary Regional Data}


By the definition of equation (2), we use the primary data to establish NP1. As can be seen from Figure 9, NP1 starts high and almost reaches 70 yuan, starts to decline to less than 20 yuan on 8 July 2015, rises a little, and reaches 50 yuan on 1 February 2016. After that, NP1 suddenly declines to an unbelievably low price, which is close to zero. Thereafter, NP1 starts to rise again, reaches 50 yuan three times in 2016, decreases to close to zero several times after February 2017, and finally reaches 10 yuan by the end of 2017.

It seems that NP1 is declining from June 2014 to December 2017, which indicates that national carbon prices are overpriced at the beginning of the sample. Moreover, NP1 varies substantially, with Table 10 showing that NP1 fluctuates considerably, with a standard deviation of 12.90 (from Table 12). The highest price is 69.12 yuan and the lowest price is only 0.22 yuan. The mean is 27.606 yuan and the median is 27.335 yuan, which are very close.

\section{[Figure 9 goes here]}

It is important to understand the relationship of NP1 with the regional prices. From Figure 10, it can be seen that the regional markets have substantial variations, both in terms of their own variations and also in comparison with the other regions. The prices in Beijing continues to fluctuate around 50, the prices in Shenzhen, Guangdong and Tianjin continue to decrease, the prices in Shanghai decrease at first and then increase, and the prices in Chongqing decrease at first, increase suddenly, and then decrease.

\section{[Figure 10 goes here]}

However, NP1 fluctuates more than the regional prices, with many increases and decreases throughout the sample period. NP1 is close to the highest NP1 values on several occasions, such as on 3 September 2014, and is also close to the lowest NP1 values on several occasions, such as on 8 April 2016. This is mainly because of a lack of liquidity in the regional markets, and where the prices in the different regions can be quite different. As a result, a lack of liquidity is such that NP1 on some days may be influenced substantially by one regional market, and hence is not representative of all the regions.

Table 10 shows that NP1 is highly correlated with prices in Guangdong and Shenzhen, with correlations of 0.646 and 0.636 , respectively. This is not surprising, as 
Guangdong is the largest regional market by volume and Shenzhen is the earliest market with high liquidity. The correlation of NP1 with prices in Tianjin is 0.539, which is surprising. The Tianjin market is small, both by volume and turnover, and it is much less liquid than Shenzhen, Guangdong, Beijing and Shanghai. The correlations of NP1 with the prices in Chongqing and Shanghai are low, at 0.383 and 0.295 , respectively. Beijing has the lowest correlation with NP1, at 0.153 . The low correlation arises because Beijing has few carbon permits and established many serious regulations for participation, so the prices in Beijing are much more stable than in the other regional markets.

\section{[Table 10 goes here]}

\section{Establishing National Prices Using Secondary Regional Data}

By the definition in equation (4), we can establish national prices based on secondary data (NP2). From Figure 11, it can be seen that NP2 starts from 60 yuan, then declines to 17.36 very quickly, and varies around 30 yuan. On 18 June 2015, NP2 declines to 20 yuan, and increases to 40 yuan on 10 November 2015. Thereafter, NP2 declines and basically fluctuates around 20 yuan until 28 June 2017. During this period, NP2 reaches 50 yuan on 16 January 2017. After 28 June 2017, NP2 decreases and reaches 1.76 yuan on 10 October 2017, and then varies around 20 yuan.

\section{[Figure 11 goes here]}

Similar to the calculated national carbon emissions prices using primary data, NP1, using secondary data shows that NP2 has a trend that decreases from 2014 to 2017. For NP2, the highest price is 59.76 yuan and the lowest is 1.52 yuan. The mean and median are close, at 24.050 and 23.835 yuan, respectively, with a standard deviation of 8.665. It seems that NP2 does not vary inordinately

The relationship between the regional prices and NP2 is worth noting Figure 12 shows that prices in Beijing are stable, varies around 50 for much of the time, and is the highest regional carbon emissions price., so that NP2 is less than the Beijing prices. In fact, NP2 is also less than the Shenzhen prices. The prices in Guangdong and Shanghai both decline from high prices. After decreasing, Shanghai prices increase to prices that are close to Shenzhen prices, which means that NP2 is also below Shanghai prices. While Guangdong prices remain relatively low after decreasing, NP2 is generally less than Guangdong prices. Even if Chongqing prices 
also continue to decrease, it does not seem to matter greatly as there is not an especially high correlation between NP2 and Chongqing prices.

\section{[Figure 12 goes here]}

Table 11 shows that NP2 is highly correlated with Hubei prices, with a correlation of 0.600 , as well as with Tianjin, with a correlation of 0.608 . It is not surprising that there is a high correlation between NP2 and Hubei as Hubei accounts for a large proportion of the total turnovers in the seven markets, and also has high liquidity. However, the Tianjin market is not especially important, regardless of turnovers, volumes or trading frequencies. Both Guangdong and Shenzhen are highly correlated with NP2, with correlations of 0.525 and 0.543, respectively. Shenzhen and Guangdong are both important based on turnovers and volumes. The correlation of NP2 with Chongqing is lower, at 0.428 . Shanghai prices are not very highly correlated with NP2, with at 0.235 . The correlation of NP2 with Beijing prices is unbelievably low, at 0.035, which suggests that Beijing does not have a great impact on NP2.

\section{[Table 11 goes here]}

\section{Comparing National Prices from Primary and Secondary Data}

As discussed above, NP1 is calculated using the primary data from six regional markets, while NP2 is calculated using the secondary data from seven regional markets. For Shenzhen, Beijing, Chongqing, Guangdong, Shanghai and Tianjin, most of T1 and T2 are highly correlated, as are V1 and V2. Therefore, any differences between NP1 and NP2 arise mainly from the Hubei market.

By comparing Figures 10 and 11, it is clear that both NP1 and NP2 start from high prices, and decline to low prices. NP1 in the beginning of the sample is higher, at 70 yuan, while NP2 in the beginning is 60 yuan. After 2016, both NP1 and NP2 vary around 20 yuan, but NP1 reaches 20 at the end of 2017, while NP2 reaches 10 yuan at the end of 2017. Even though NP1 and NP2 both tend to decrease from 2014 to 2017, they do not look very similar.

Table 12 shows that NP1 has higher mean, median and maximum value than does NP2, but NP2 has a higher minimum value than does NP1. The standard deviations show that the fluctuating range of NP1 is greater than that of NP2. The standard deviation of NP1 is 12.90 , which is dramatically larger than for NP2, at 8.67. The 
skewness and kurtosis scores of NP1 are different from those of NP2, and show that the distributions are not normal. All these descriptive statistics support the case that NP1 is noticeably different from NP2.

Table 13 also supports this conclusion. The correlation of NP1 and NP2 is 0.688, which means that NP1 and NP2 are quite different over the sample period. The differences between NP1 and NP2 arise mainly from Hubei, which is not surprising as Hubei is important in terms of both turnovers and volumes. Therefore, Hubei cannot be ignored in establishing national carbon emissions prices, so that using secondary data from seven regional markets would seem to be more appropriate and accurate in establishing national carbon emissions prices than using primary data from six regional markets.

\section{[Tables 12 and 13 go here]}

\section{Concluding Remarks}

The purpose of the paper was to establish national carbon emissions prices for China, based on available regional carbon emissions markets. A carbon emissions trading market is widely seen as one of the most important methods for reducing carbon emissions in China and internationally, as well as being a financial tradeable commodity.

The Central Government of the People's Republic of China decided to establish several regional carbon markets in 2011. By the end of 2017, eight regional markets had been established. Moreover, the Central Government declared the establishment of a national carbon emissions market in September 2017, starting with the power generation industry.

The experience of the regional markets will be helpful in establishing a national carbon emissions market. One of the most pressing issues associated with the national market that is under construction is to determine a national price, which should be closely related to the regional prices, turnovers, and volumes. In order to establish a national price, it is necessary to obtain data from the regional markets.

Regional carbon emissions can be obtained from two sources, namely primary and secondary data. In this paper, we have carefully analyzed the two data sources and compared them with each other, as well as with the regional prices. The differences 
between the primary and secondary price data for the regional markets, and subsequently with the national market, have been examined. National prices based on the primary and secondary sources have been established, for the first time, and the advantages of each have been analyzed.

Primary data from six regions are available, as are secondary data from eight regions, the difference being the lack of primary data for Hubei and Fujian. Hubei is too large to be ignored, whereas Fujian is not as important. Consequently, the calculated national prices based on the primary data from the six regional markets in Beijing, Guangdong, Chongqing, Shanghai, Shenzhen and Tianjin, are markedly different from the national prices based on the secondary data from the six regional markets together with Hubei.

The national carbon emissions prices are based on corresponding prices in the regional markets, which should have an important impact on the national carbon emissions market that is under construction in China. The paper has established two sets of national carbon emissions prices as a contribution to the determination of a national carbon emissions pricing scheme, as well as for other regions and countries worldwide. 
Table 1

Descriptive Statistics for Regional Prices

\begin{tabular}{|c|c|c|c|c|c|c|c|}
\hline Region & Mean & Median & Max & Min & Std. Dev. & Skewness & Kurtosis \\
\hline Beijing & 50.06 & 51 & 77 & 31.84 & 6.35 & 0.04 & 5.77 \\
\hline Shanghai & 24.79 & 28.84 & 44.91 & 0.085 & 12.03 & -0.36 & 1.64 \\
\hline Shenzhen & 42.65 & 37.85 & 122.97 & 2.12 & 18.15 & 1.16 & 3.73 \\
\hline Guangdong & 24.29 & 15.57 & 77 & 6.93 & 17.80 & 1.47 & 3.66 \\
\hline Hubei & 20.22 & 22.01 & 29.25 & 10.07 & 4.45 & -0.26 & 1.64 \\
\hline Tianjin & 19.99 & 22.39 & 50.11 & 7 & 7.74 & 0.34 & 3.08 \\
\hline Chongqing & 17.42 & 13.5 & 47.52 & 1 & 11.71 & 0.35 & 1.98 \\
\hline Fujian & 30.16 & 30 & 42.28 & 17.26 & 6.29 & -0.14 & 1.75 \\
\hline
\end{tabular}


Table 2

Descriptive Statistics for Regional Turnovers

\begin{tabular}{|c|c|c|c|c|c|c|c|}
\hline Region & Mean & Median & Max & Min & Std. Dev. & Skewness & Kurtosis \\
\hline Beijing & 331946 & 4998 & 7238610 & 0 & 926834 & 4 & 23 \\
\hline Shanghai & 409556 & 5203 & 23174943 & 0 & 1697093 & 8 & 83 \\
\hline Shenzhen & 690989 & 65680 & 100000000 & 0 & 4077118 & 21 & 491 \\
\hline Guangdong & 655539 & 6763 & 47519182 & 0 & 2370102 & 11 & 173 \\
\hline Hubei & 932969 & 402938 & 29598300 & 0 & 1972580 & 8 & 93 \\
\hline Tianjin & 47955 & 0 & 11206984 & 0 & 500858 & 17 & 312 \\
\hline Chongqing & 29514 & 0 & 4457300 & 0 & 224810 & 13 & 208 \\
\hline Fujian & 229132 & 47613 & 4647190 & 0 & 560939 & 5 & 29 \\
\hline
\end{tabular}


Table 3

Descriptive Statistics for Regional Volumes

\begin{tabular}{|c|c|c|c|c|c|c|c|}
\hline Region & Mean & Median & Max & Min & Std. Dev. & Skewness & Kurtosis \\
\hline Beijing & 6588 & 100 & 154960 & 0 & 18418 & 4 & 24 \\
\hline Shanghai & 25578 & 200 & 1379977 & 0 & 102684 & 6 & 54 \\
\hline Shenzhen & 23437 & 1325 & 4000000 & 0 & 166807 & 21 & 462 \\
\hline Guangdong & 45350 & 411 & 3712999 & 0 & 172010 & 12 & 216 \\
\hline Hubei & 47372 & 19804 & 1176200 & 0 & 92212 & 6 & 49 \\
\hline Tianjin & 3419 & 0 & 827815 & 0 & 39359 & 16 & 289 \\
\hline Chongqing & 8865 & 0 & 2112607 & 0 & 82367 & 20 & 471 \\
\hline Fujian & 8114 & 1580 & 207264 & 0 & 23182 & 5 & 36 \\
\hline
\end{tabular}


Table 4

Correlations of Primary and Secondary Data - Beijing

\begin{tabular}{|c|c|c|c|c|c|c|}
\hline & T1 & V1 & P1 & T2 & V2 & P2 \\
\hline T1 & 1.000 & 0.993 & 0.064 & 0.993 & 0.987 & 0.055 \\
\hline V1 & 0.993 & 1.000 & 0.019 & 0.987 & 0.994 & 0.011 \\
\hline P1 & 0.064 & 0.019 & 1.000 & 0.065 & 0.021 & 0.986 \\
\hline T2 & 0.993 & 0.987 & 0.065 & 1.000 & 0.993 & 0.064 \\
\hline V2 & 0.987 & 0.994 & 0.021 & 0.993 & 1.000 & 0.020 \\
\hline P2 & 0.055 & 0.011 & 0.986 & 0.064 & 0.020 & 1.000 \\
\hline
\end{tabular}

Note: T1, T2, V1, V2, P1, P2 denote turnovers, volumes and prices, respectively, for Primary (1) and Secondary (2) data. 
Table 5

Correlations of Primary and Secondary Data - Shanghai

\begin{tabular}{|c|c|c|c|c|c|c|}
\hline & T1 & V1 & P1 & T2 & V2 & P2 \\
\hline T1 & 1.000 & 0.601 & 0.092 & 0.596 & 0.442 & 0.099 \\
\hline V1 & 0.601 & 1.000 & -0.182 & 0.401 & 0.554 & -0.077 \\
\hline P1 & 0.092 & -0.182 & 1.000 & 0.123 & -0.065 & 0.959 \\
\hline T2 & 0.596 & 0.401 & 0.123 & 1.000 & 0.728 & 0.131 \\
\hline V2 & 0.442 & 0.554 & -0.065 & 0.728 & 1.000 & -0.058 \\
\hline P2 & 0.099 & -0.077 & 0.959 & 0.131 & -0.058 & 1.000 \\
\hline
\end{tabular}

Note: T1, T2, V1, V2, P1, P2 denote turnovers, volumes and prices, respectively, for Primary (1) and Secondary (2) data. 
Table 6

Correlations of Primary and Secondary Data - Guangdong

\begin{tabular}{|c|c|c|c|c|c|c|}
\hline & T1 & V1 & P1 & T2 & V2 & P2 \\
\hline T1 & 1.000 & 0.973 & -0.103 & 0.624 & 0.591 & -0.100 \\
\hline V1 & 0.973 & 1.000 & -0.146 & 0.542 & 0.580 & -0.142 \\
\hline P1 & -0.103 & -0.146 & 1.000 & -0.077 & -0.150 & 0.998 \\
\hline T2 & 0.624 & 0.542 & -0.077 & 1.000 & 0.941 & -0.074 \\
\hline V2 & 0.591 & 0.580 & -0.150 & 0.941 & 1.000 & -0.146 \\
\hline P2 & -0.100 & -0.142 & 0.998 & -0.074 & -0.146 & 1.000 \\
\hline
\end{tabular}

Note: T1, T2, V1, V2, P1, P2 denote turnovers, volumes and prices, respectively, for Primary (1) and Secondary (2) data. 
Table 7

Correlations of Primary and Secondary Data - Tianjin

\begin{tabular}{|c|c|c|c|c|c|c|}
\hline & T1 & V1 & P1 & T2 & V2 & P2 \\
\hline T1 & 1.000 & 0.953 & -0.040 & 0.933 & 0.886 & -0.040 \\
\hline V1 & 0.953 & 1.000 & -0.067 & 0.902 & 0.950 & -0.067 \\
\hline $\mathbf{P 1}$ & -0.040 & -0.067 & 1.000 & -0.035 & -0.062 & 0.991 \\
\hline T2 & 0.933 & 0.902 & -0.035 & 1.000 & 0.950 & -0.036 \\
\hline V2 & 0.886 & 0.950 & -0.062 & 0.950 & 1.000 & -0.063 \\
\hline P2 & -0.040 & -0.067 & 0.991 & -0.036 & -0.063 & 1.000 \\
\hline
\end{tabular}

Note: T1, T2, V1, V2, P1, P2 denote turnovers, volumes and prices, respectively, for Primary (1) and Secondary (2) data. 
Table 8

Correlations of Primary and Secondary Data - Chongqing

\begin{tabular}{|c|c|c|c|c|c|c|}
\hline & T1 & V1 & P1 & T2 & V2 & P2 \\
\hline T1 & 1.000 & 0.619 & -0.083 & 0.830 & 0.595 & -0.084 \\
\hline V1 & 0.619 & 1.000 & -0.130 & 0.516 & 0.982 & -0.131 \\
\hline P1 & -0.083 & -0.130 & 1.000 & -0.080 & -0.121 & 0.999 \\
\hline T2 & 0.830 & 0.516 & -0.080 & 1.000 & 0.526 & -0.081 \\
\hline V2 & 0.595 & 0.982 & -0.121 & 0.526 & 1.000 & -0.122 \\
\hline P2 & -0.084 & -0.131 & 0.999 & -0.081 & -0.122 & 1.000 \\
\hline
\end{tabular}

Note: T1, T2, V1, V2, P1, P2 denote turnovers, volumes and prices, respectively, for Primary (1) and Secondary (2) data. 
Table 9

Correlations of Primary and Secondary Data - Shenzhen

\begin{tabular}{|c|c|c|c|c|c|c|}
\hline & T1 & V1 & P1 & T2 & V2 & P2 \\
\hline T1 & 1.000 & 0.960 & -0.066 & 0.972 & 0.906 & -0.065 \\
\hline V1 & 0.960 & 1.000 & -0.102 & 0.938 & 0.947 & -0.099 \\
\hline P1 & -0.066 & -0.102 & 1.000 & -0.046 & -0.088 & 0.987 \\
\hline T2 & 0.972 & 0.938 & -0.046 & 1.000 & 0.928 & -0.048 \\
\hline V2 & 0.906 & 0.947 & -0.088 & 0.928 & 1.000 & -0.098 \\
\hline P2 & -0.065 & -0.099 & 0.987 & -0.048 & -0.098 & 1.000 \\
\hline
\end{tabular}

Note: T1, T2, V1, V2, P1, P2 denote turnovers, volumes and prices, respectively, for Primary (1) and Secondary (2) data. 
Table 10

Correlations of National (NP1) and Primary Regional Prices

\begin{tabular}{|c|c|c|c|c|c|c|c|}
\hline & Shenzhen & Beijing & Chongqing & Guangdong & Shanghai & Tianjin & NP1 \\
\hline Shenzhen & 1.000 & 0.105 & 0.304 & 0.741 & 0.220 & 0.651 & 0.636 \\
\hline Beijing & 0.105 & 1.000 & 0.275 & 0.411 & 0.493 & -0.102 & 0.153 \\
\hline Chongqing & 0.304 & 0.275 & 1.000 & 0.470 & 0.080 & 0.506 & 0.383 \\
\hline Guangdong & 0.741 & 0.411 & 0.470 & 1.000 & 0.469 & 0.568 & 0.646 \\
\hline Shanghai & 0.220 & 0.493 & 0.080 & 0.469 & 1.000 & -0.024 & 0.295 \\
\hline Tianjin & 0.651 & -0.102 & 0.506 & 0.568 & -0.024 & 1.000 & 0.539 \\
\hline NP1 & 0.636 & 0.153 & 0.383 & 0.646 & 0.295 & 0.539 & 1.000 \\
\hline
\end{tabular}


Table 11

Correlations of National (NP2) and Secondary Regional Prices

\begin{tabular}{|c|c|c|c|c|c|c|c|c|}
\hline & Shenzhen & Beijing & Chongqing & Guangdong & Shanghai & Tianjin & Hubei & NP2 \\
\hline Shenzhen & 1.000 & 0.114 & 0.305 & 0.729 & 0.253 & 0.654 & 0.573 & 0.543 \\
\hline Beijing & 0.114 & 1.000 & 0.278 & 0.419 & 0.559 & -0.104 & -0.222 & 0.035 \\
\hline Chongqing & 0.305 & 0.278 & 1.000 & 0.474 & 0.118 & 0.515 & 0.497 & 0.428 \\
\hline Guangdong & 0.729 & 0.419 & 0.474 & 1.000 & 0.555 & 0.556 & 0.487 & 0.525 \\
\hline Shanghai & 0.253 & 0.559 & 0.118 & 0.555 & 1.000 & -0.037 & 0.024 & 0.235 \\
\hline Tianjin & 0.654 & -0.104 & 0.515 & 0.556 & -0.037 & 1.000 & 0.785 & 0.608 \\
\hline Hubei & 0.573 & -0.222 & 0.497 & 0.487 & 0.024 & 0.785 & 1.000 & 0.600 \\
\hline NP2 & 0.543 & 0.035 & 0.428 & 0.525 & 0.235 & 0.608 & 0.600 & 1.000 \\
\hline
\end{tabular}


Table 12

Descriptive Statistics for National Prices from

Primary (NP1) and Secondary (NP2) Data

\begin{tabular}{|c|c|c|c|c|c|c|c|}
\hline Data & Mean & Median & Max & Min & Std. Dev. & Skewness & Kurtosis \\
\hline NP1 & 27.61 & 27.34 & 69.12 & 0.22 & 12.90 & 0.30 & 2.87 \\
\hline NP2 & 24.05 & 23.84 & 59.76 & 1.52 & 8.67 & 0.44 & 3.98 \\
\hline
\end{tabular}


Table 13

Correlations of National Prices from

Primary (NP1) and Secondary (NP2) Data

\begin{tabular}{|c|c|c|}
\hline Data & NP1 & NP2 \\
\hline NP1 & 1.000 & 0.688 \\
\hline NP2 & 0.688 & 1.000 \\
\hline
\end{tabular}


Figure 1

Primary (P1) and Secondary (P2) Prices - Beijing

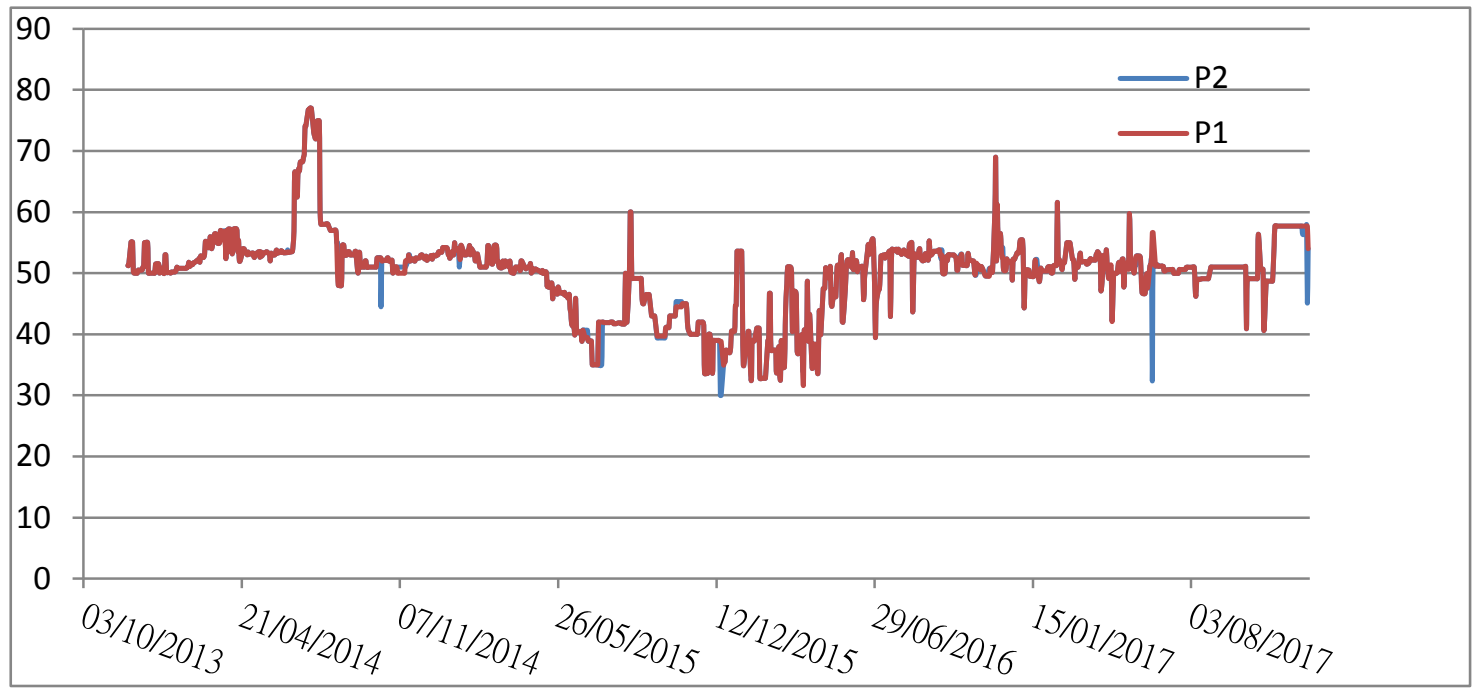


Figure 2

Primary (P1) and Secondary (P2) Prices - Shanghai

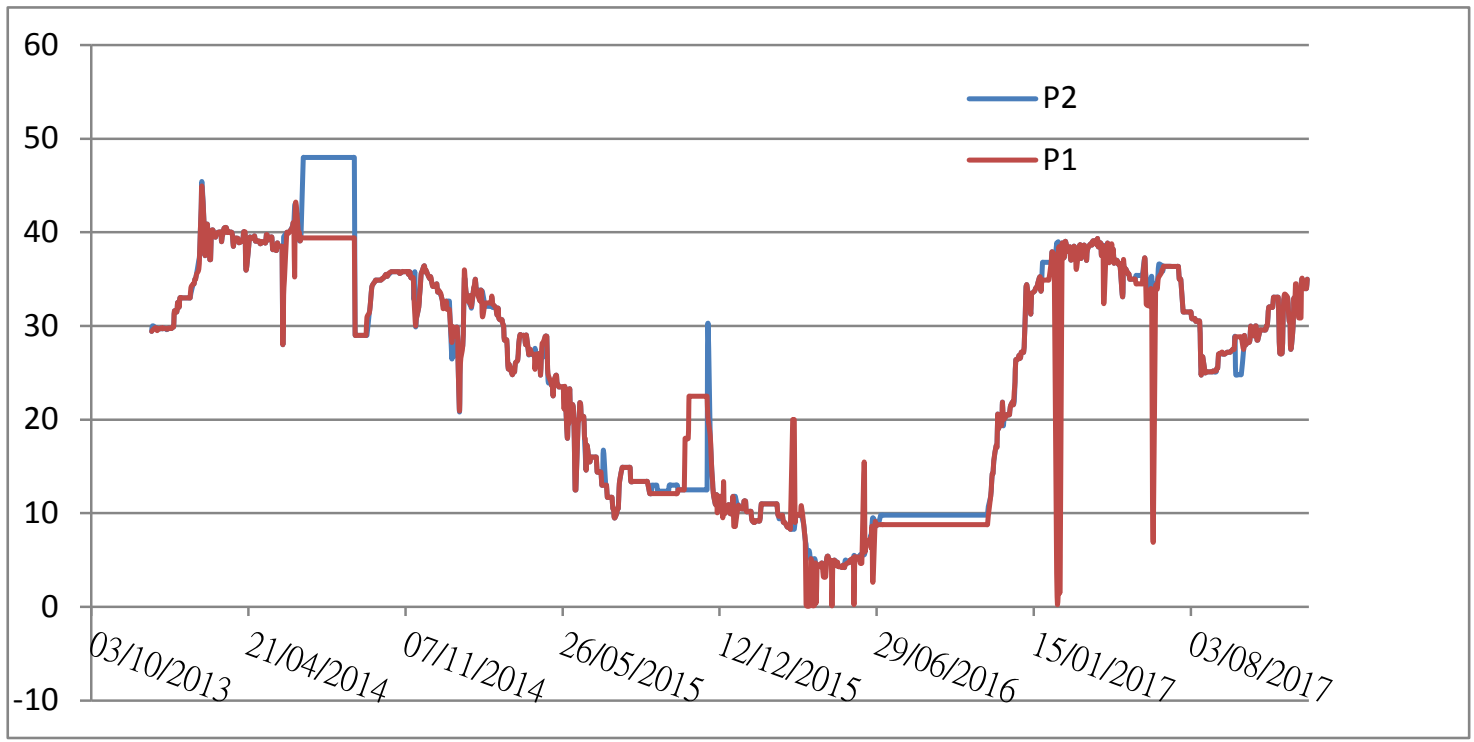


Figure 3

Primary (P1) and Secondary (P2) Prices - Guangdong

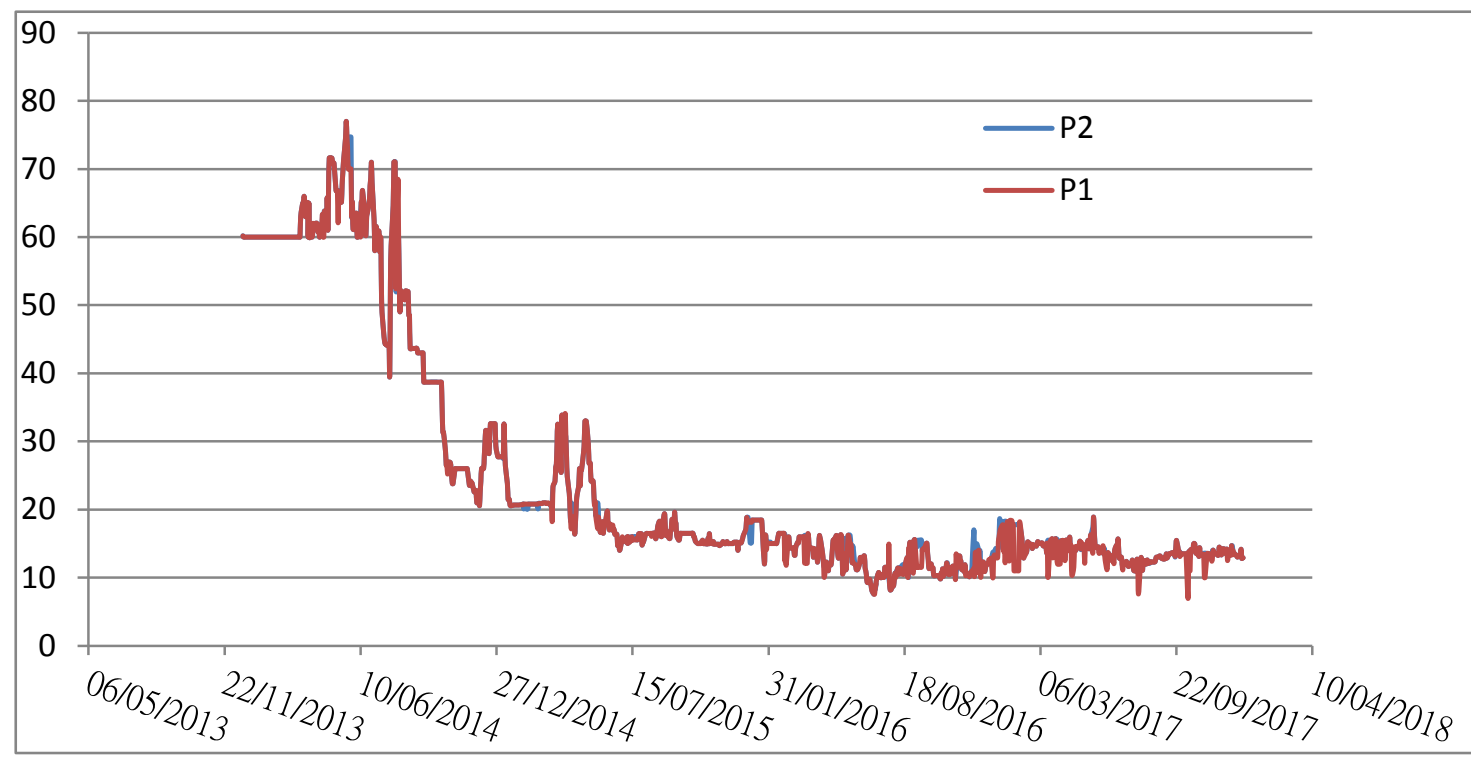

48 
Figure 4

Primary (P1) and Secondary (P2) Prices - Tianjin

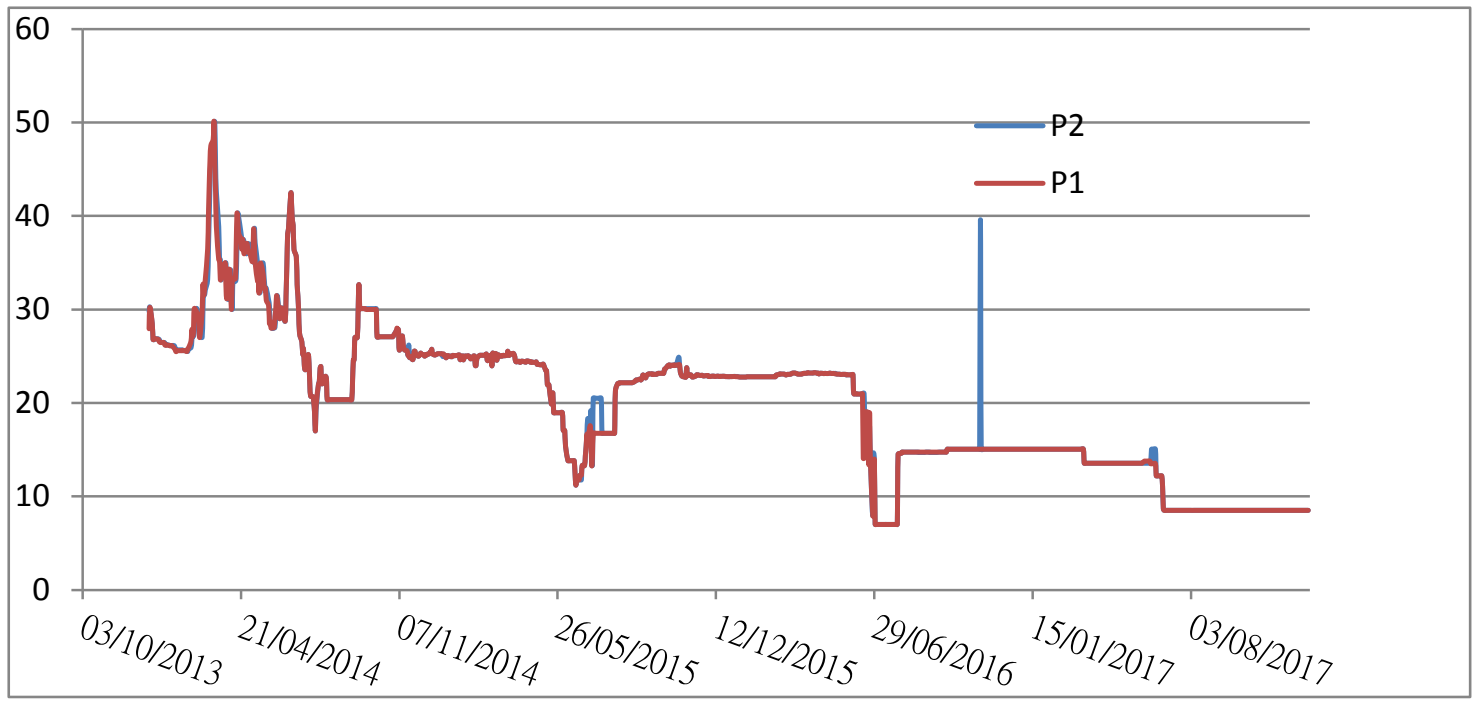


Figure 5

Primary (P1) and Secondary (P2) Prices - Chongqing

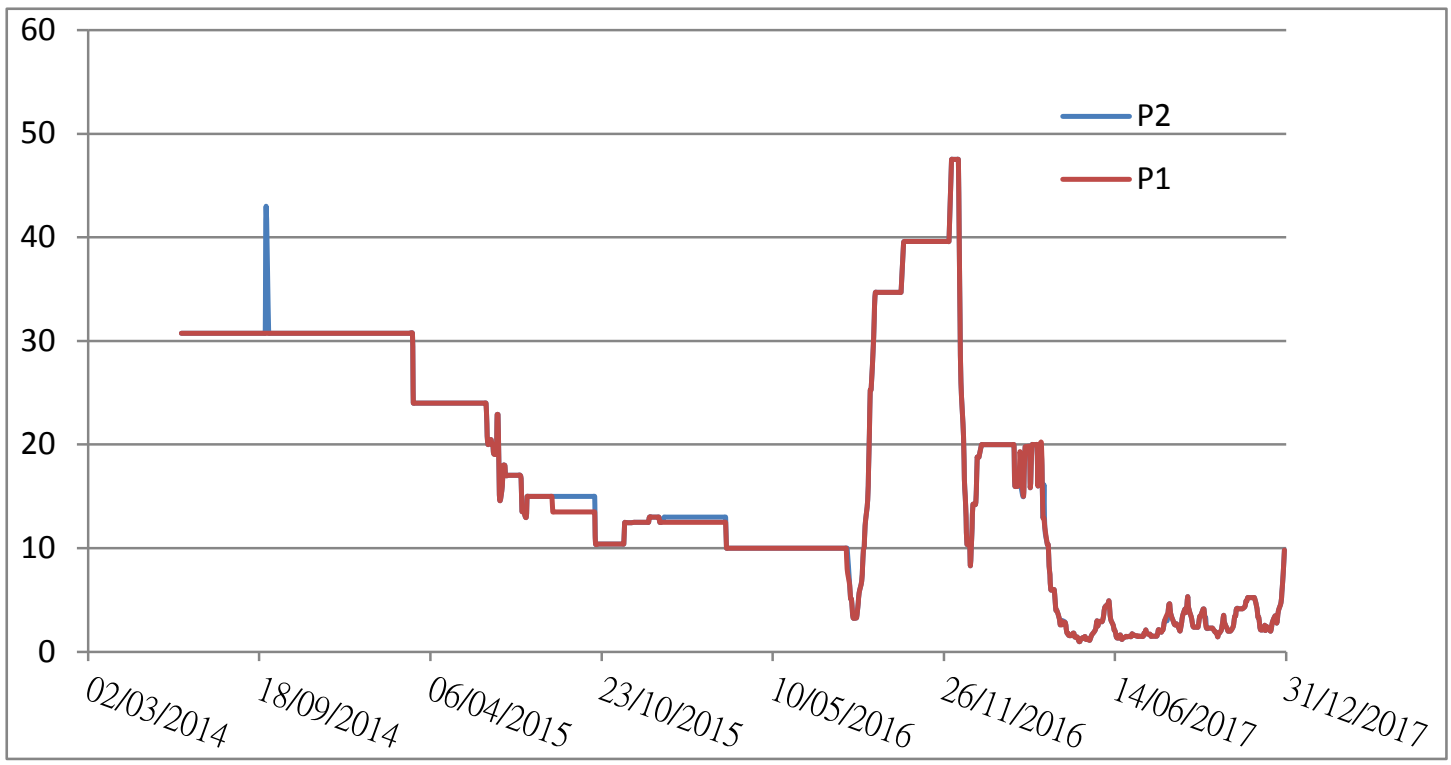


Figure 6

Primary (P1) and Secondary (P2) Prices - Shenzhen

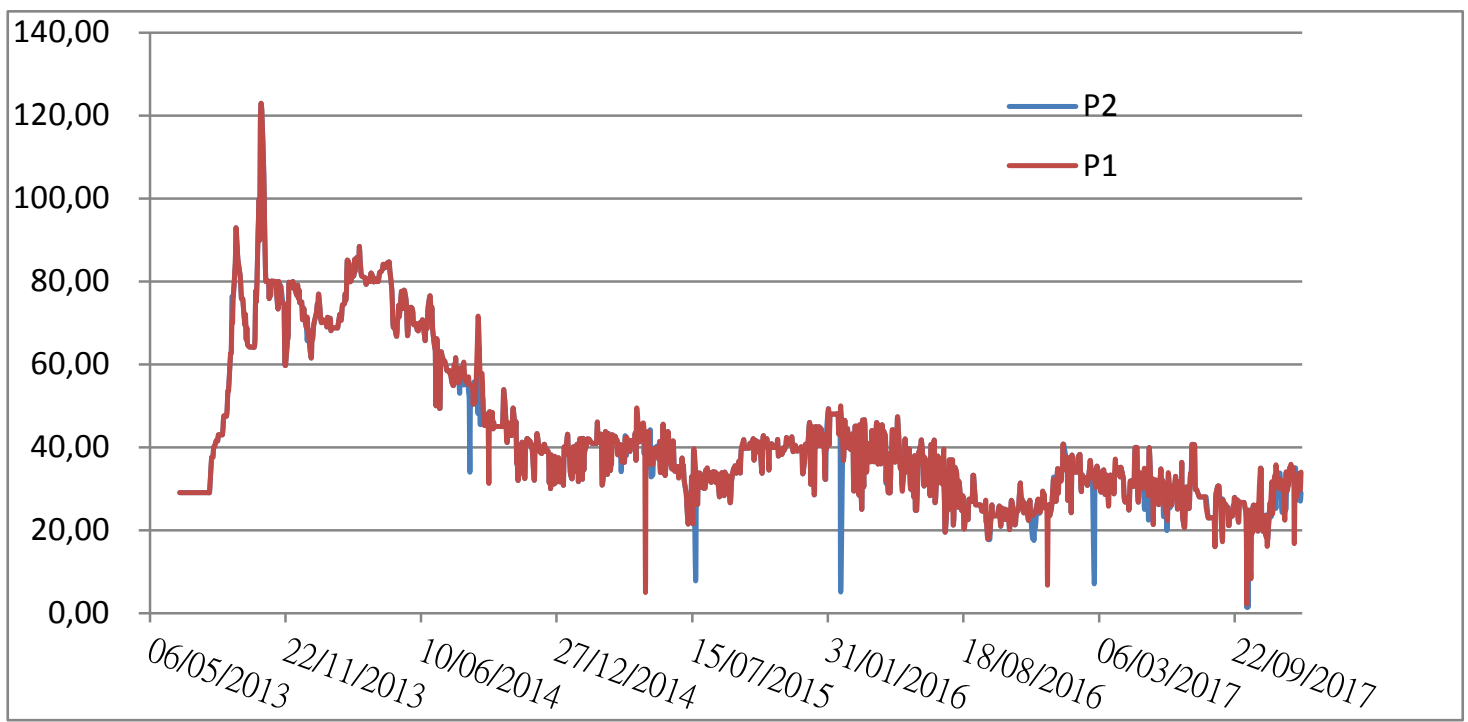


Figure 7

Secondary Prices - Hubei

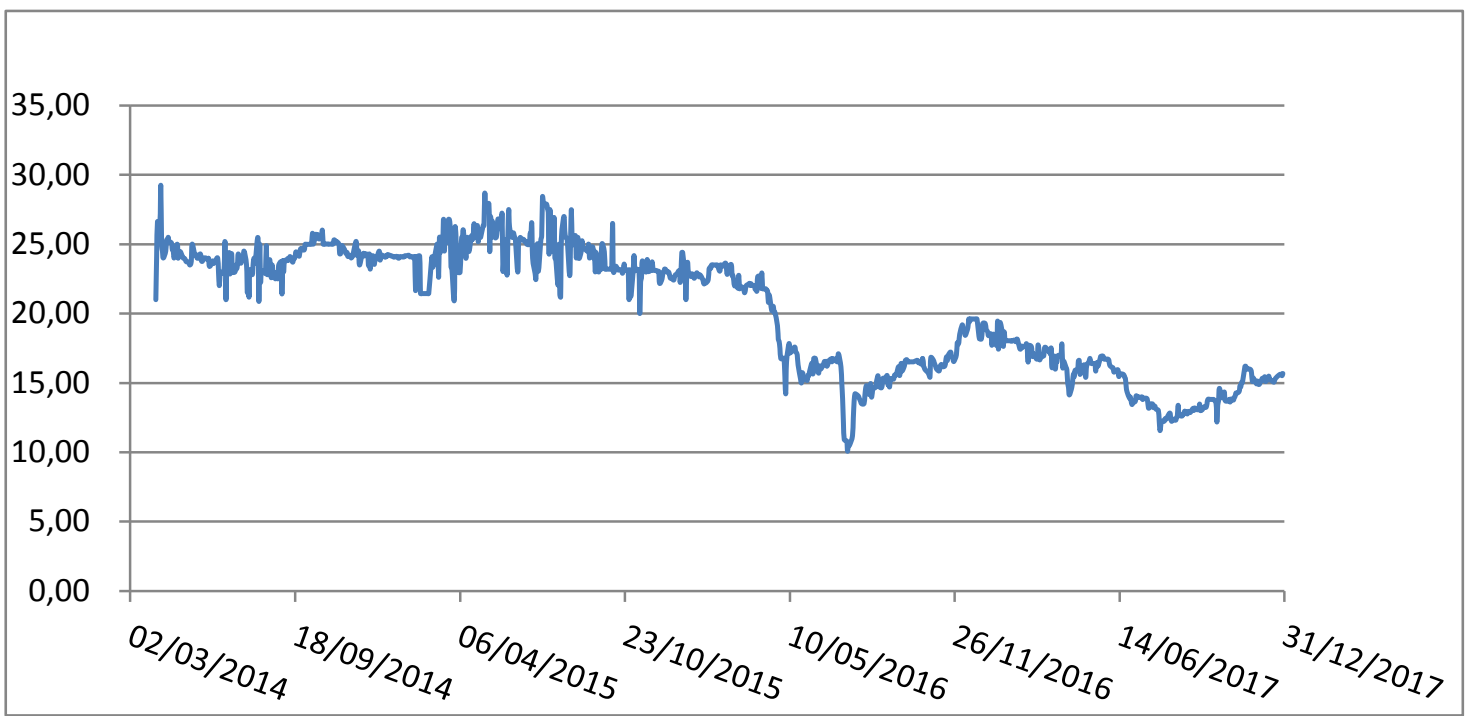


Figure 8

Secondary Prices - Fujian

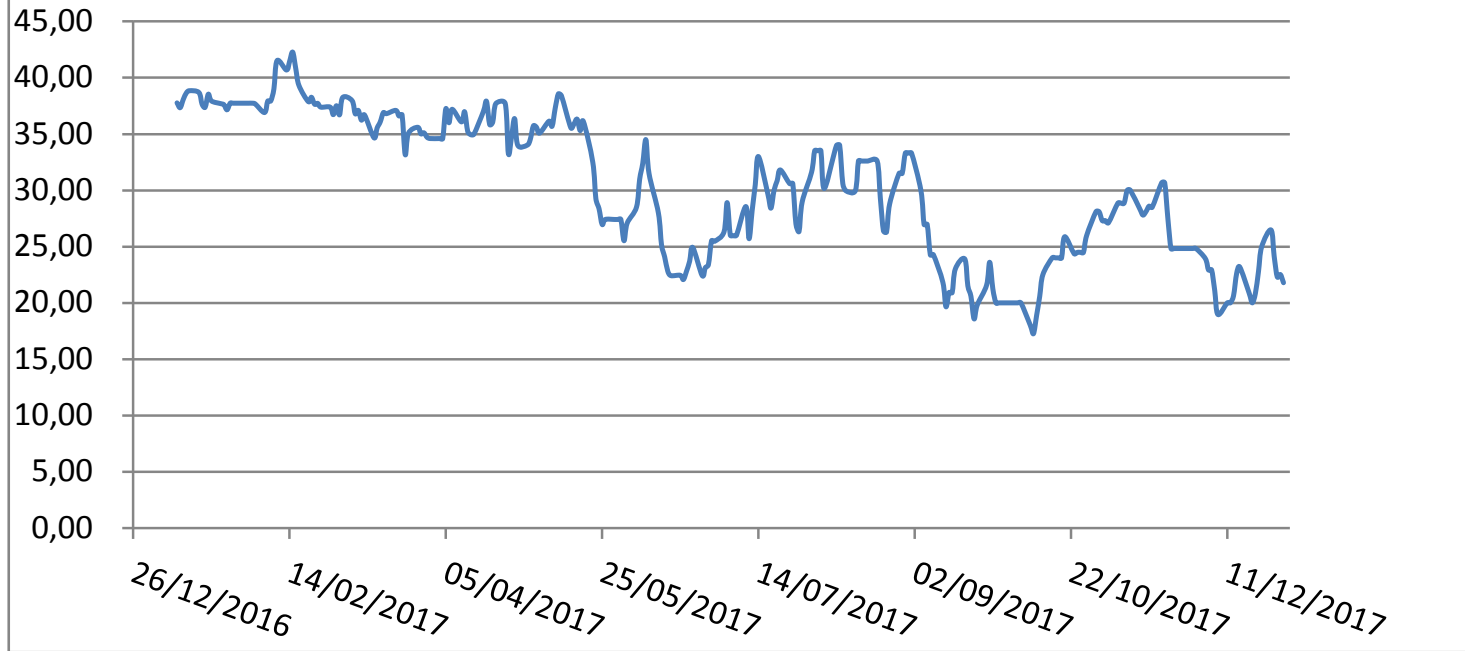


Figure 9

National Prices Using Primary Data

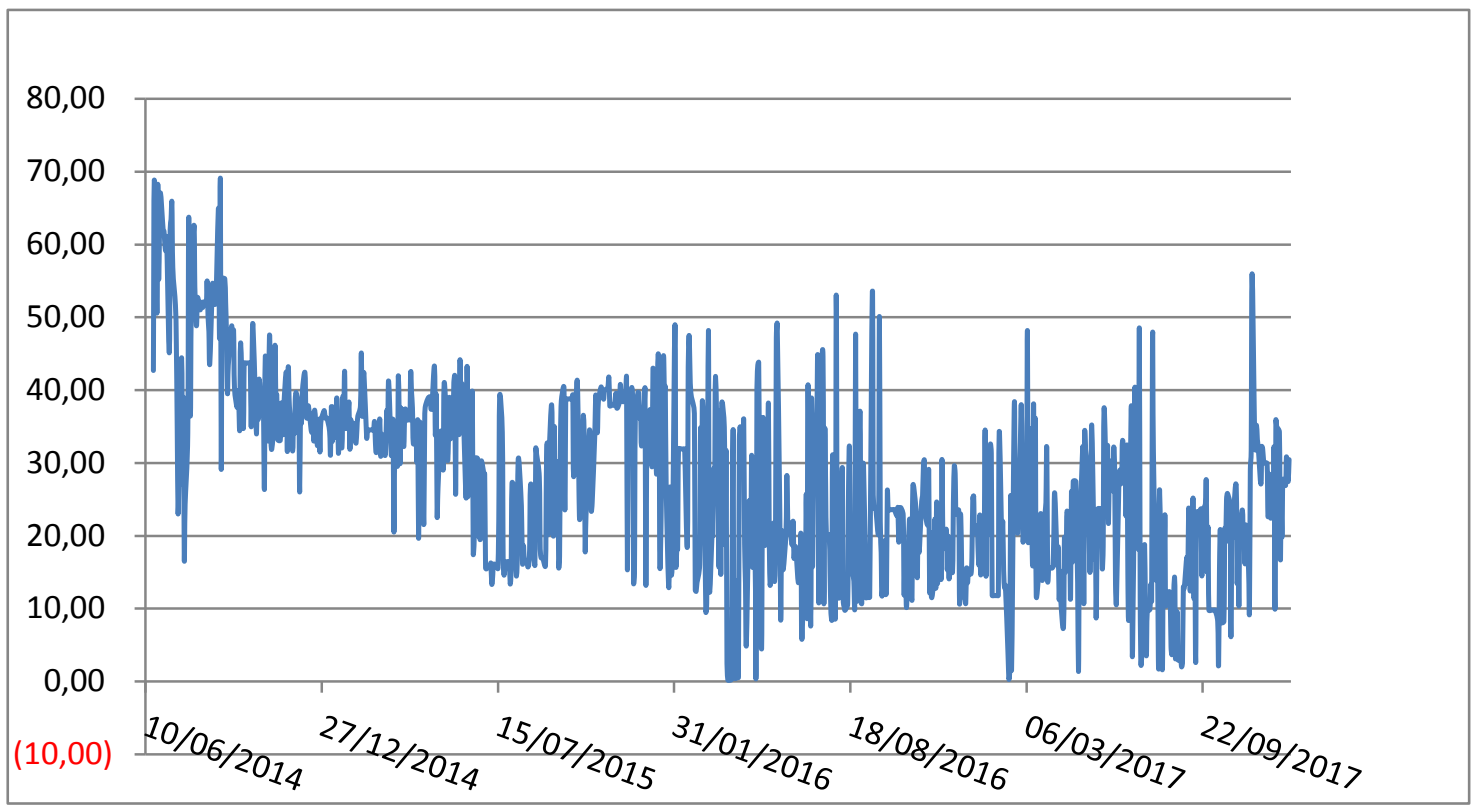


Figure 10

Calculating National Prices Using Primary Regional Data

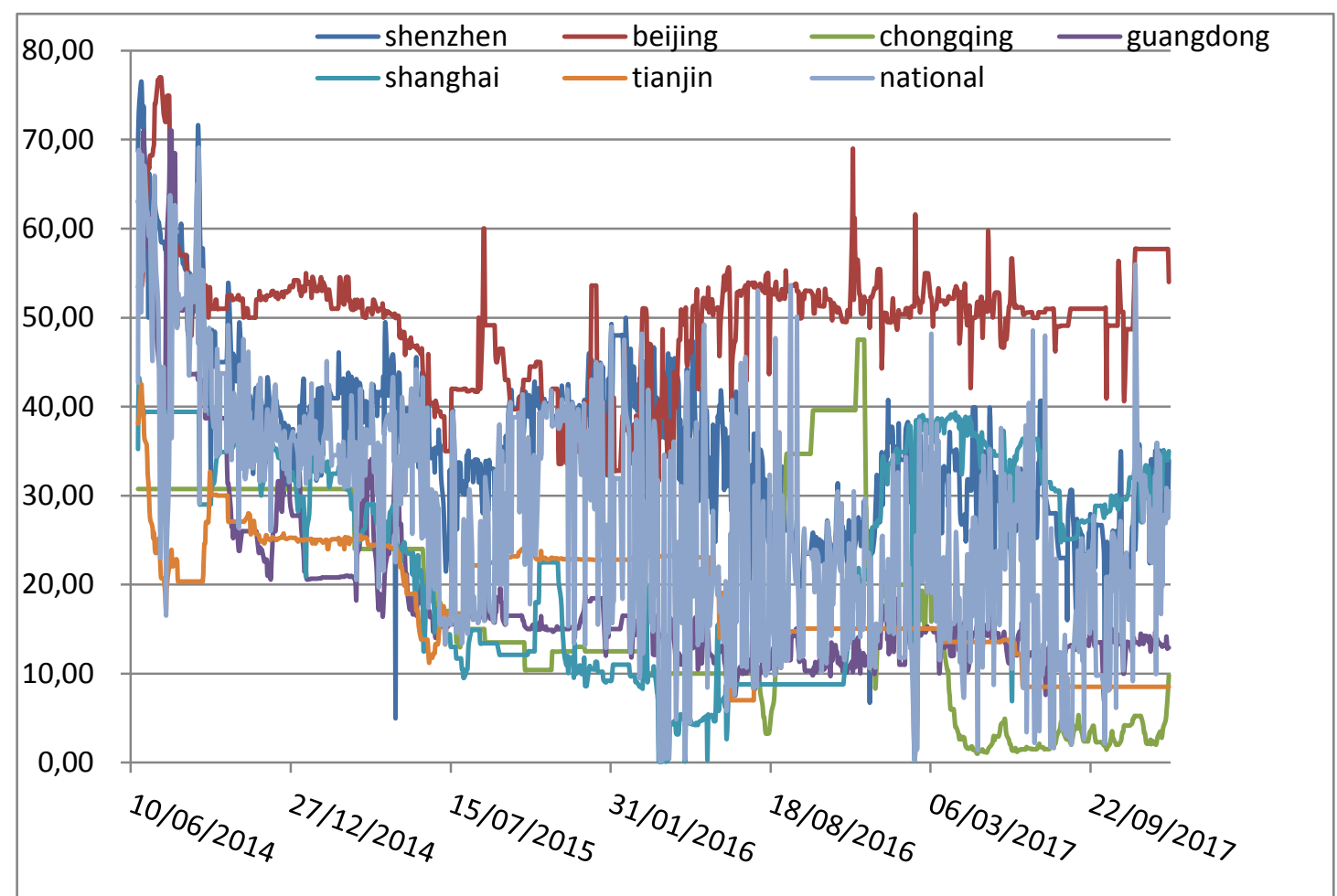


Figure 11

National Prices Using Secondary Data

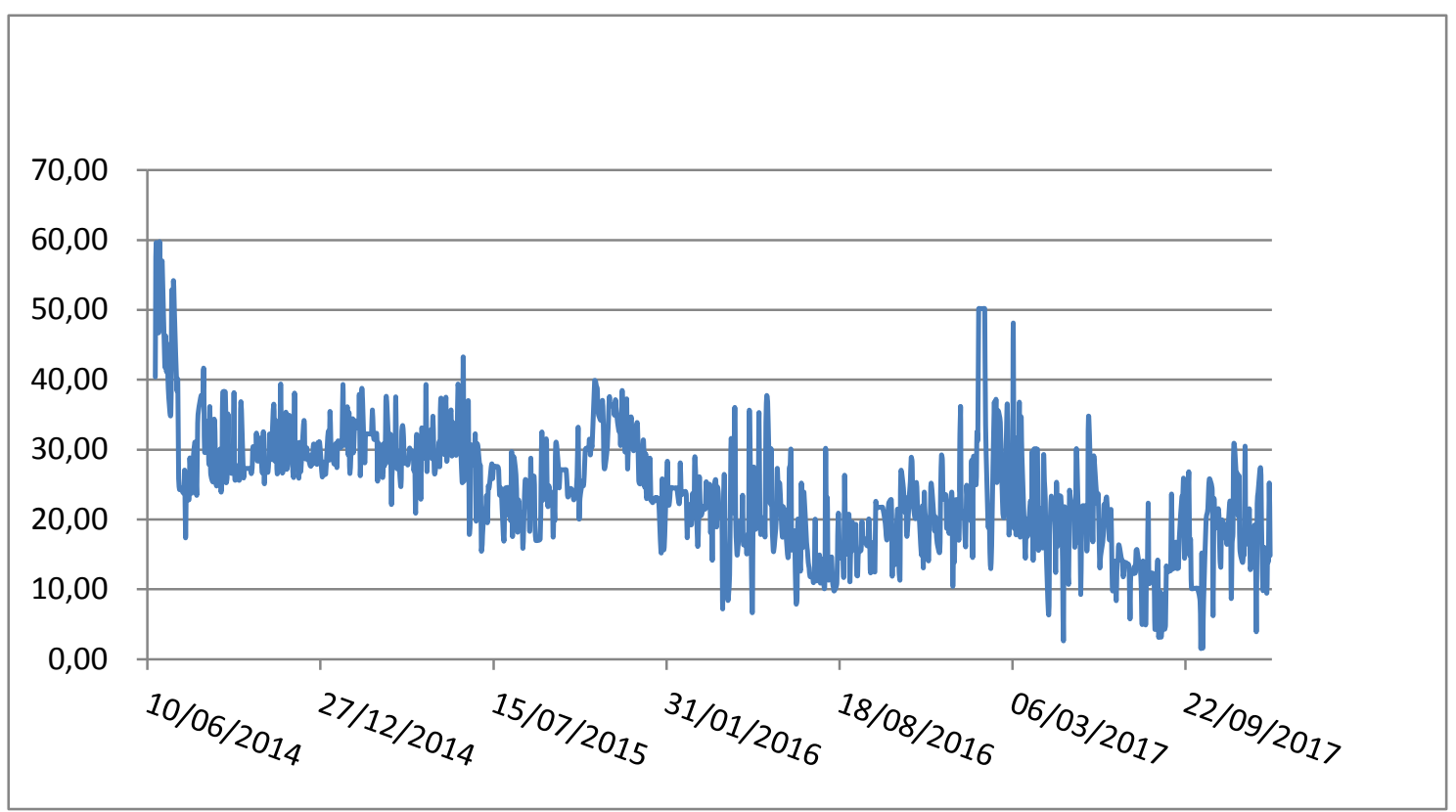


Figure 12

Calculating National Prices Using Secondary Regional Data

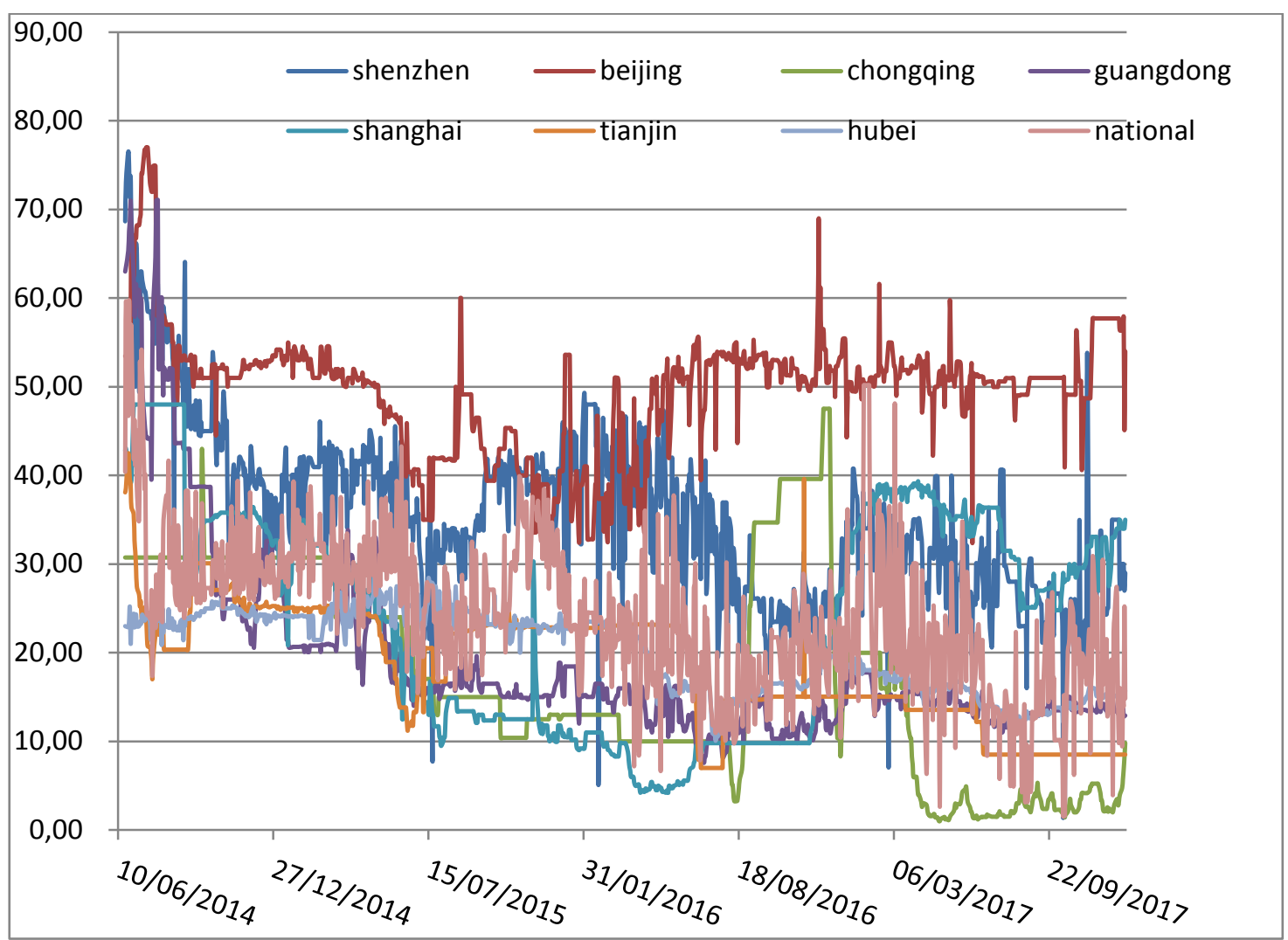




\section{References}

Bohringer, C., A. Lange and T.F. Rutherford (2014), Optimal emission pricing in the presence of international spillover: Decomposing leakage and terms-of-trade motives, Journal of Public Economics, 110, 101-111.

Cetin, U. and M. Verschuere (2009), Pricing and hedging in carbon emissions markets, International Journal of Theoretical and Applied Finance, 12(7), 949-967.

Chang, C.-L. and M. McAleer (2018), The fiction of full BEKK: Pricing fossil fuels and carbon emissions, to appear in Finance Research Letters.

(https://doi.org/10.1016/i.frl.2018.03.008).

Chang, C.-L., M. McAleer and G.D. Zuo (2017), Volatility spillovers and causality of carbon emissions, oil and coal spot and futures for the EU and USA, Sustainability, 9(10:1789), 1-21.

Dhakal, S. (2009), Urban energy use and carbon emissions from cities in China and policy implications, Energy Policy, 37(11), 4208-4219.

Lia, J. and M. Colombier (2008), Managing carbon emissions in China through building energy efficiency, Journal of Environmental Management, 90(8), 2436-2447.

Lo, A.Y. (2013), Carbon trading in a socialist market economy: Can China make a difference, Ecological Economics, 87, 72-74.

Lo, A.Y. (2016), Challenges to the development of carbon markets in China, Climate Policy, 16, 109-124.

Reboredo, J.C. (2014), Volatility spillovers between the oil market and the European Union carbon emission market, Economic Modelling, 36, 229-234.

Zhang, X.-P. and X.-M. Cheng (2009), Energy consumption, carbon emissions, and economic growth in China, Ecological Economics, 26(10), 2706-2712. 